\title{
Identification of the Regulatory Components Mediated by the Cyclic di-GMP Receptor Filp and Its Interactor PilZX3 and Functioning in Virulence of Xanthomonas oryzae pv. oryzae
}

\author{
Muhammad Umar Shahbaz,, ${ }^{1,2}$ Shanshan Qian, ${ }^{1}$ Fei Yun, ${ }^{3}$ Jie Zhang, ${ }^{1}$ Chao Yu, ${ }^{1}$ Fang Tian, ${ }^{1}$ \\ Fenghuan Yang, ${ }^{1,+}$ and Huamin Chen ${ }^{1,+}$ \\ ${ }^{1}$ State Key Laboratory for Biology Plant Diseases and Insect Pests, Institute of Plant Protection, Chinese Academy of \\ Agricultural Sciences, Beijing 100193, China \\ ${ }^{2}$ Plant Pathology Section, Plant Pathology Research Institute, AARI, Faisalabad 38850, Pakistan \\ ${ }^{3}$ National Tobacco Cultivation and Physiology and Biochemistry Research Centre/Key Laboratory for Tobacco Cultivation of \\ Tobacco Industry, Henan Agricultural University, Zhengzhou 450002, China
}

Accepted 24 July 2020.

\begin{abstract}
The degenerate GGDEF/EAL domain protein Filp was previously shown to function as a cyclic di-GMP (c-di-GMP) signal receptor through its specific interaction with an atypical PilZ domain protein PilZX3 (formerly PXO_02715) and that this interaction is involved in regulating virulence in Xanthomonas oryzae pv. oryzae. As a step toward understanding the regulatory role of Filp/PilZX3-mediated c-di-GMP signaling in the virulence of $X$. oryzae pv. oryzae, differentially expressed proteins (DEPs) downstream of Filp/PilZX3 were identified by isobaric tagging for relative and absolute quantitation (iTRAQ). A total of 2,346 proteins were identified, of which 157 displayed significant differential expression in different strains. Western blot and quantitative reverse transcription-PCR analyses showed that the expression of HrrP (histidine kinase-response regulator hybrid protein), PhrP (PhoPQ-regulated protein), ProP (prophage Lp2 protein 6) were increased in the $\triangle$ filp, $\triangle p i l Z X 3$, and $\Delta$ filp $\Delta$ pilZX3 mutant strains, while expression of CheW1 (chemotaxis protein CheW1), EdpX2 (the second EAL domain protein identified in $X$. oryzae pv. oryzae), HGdpX2 (the second HD-GYP domain protein identified in $X$. oryzae pv. oryzae) was decreased in all mutant strains compared with that in the wild type, which was consistent with the ITRAQ data. Deletion of the hrrP and proP
\end{abstract}

Muhammad Umar Shahbaz, Shanshan Qian, and Fei Yun contributed equally to this work.

The raw MS proteomics data have been deposited with the ProteomeXchange Consortium via the PRIDE partner repository under the dataset identifier PXD015734.

${ }^{\dagger}$ Corresponding authors: F. Yang; yangfenghuan@caas.cn and H. Chen; chenhuamin@caas.cn

Funding: This work was supported by the grants from National Natural Science Foundation of China (31400117 and 31671990), National Key R\&D Program of China (2016YFD0300701) and China Postdoctoral Science Foundation (2014T70149).

*The $\boldsymbol{e}$-Xtra logo stands for "electronic extra" and indicates there are supplementary figures, a supplementary table, and a supplementary file published online.

The author(s) declare no conflict of interest.

C 2020 The American Phytopathological Society genes resulted in significant increases in virulence, whereas deletion of the $c h e W 1, h G d p X 2$, or $t d r X 2$ genes resulted in decreased virulence. Enzyme assays indicated that EdpX2 and HGdpX2 were active phosphodiesterases (PDEs). This study provides a proteomic description of putative regulatory pathway of Filp and PilZX3 and characterized novel factors that contributed to the virulence of $X$. oryzae pv. oryzae regulated by c-di-GMP signaling.

Keywords: cyclic di-GMP receptor, degenerated PilZ domain protein, relative and absolute quantitation (iTRAQ), virulence, Xanthomonas oryzae pv. oryzae

Cyclic di-GMP (c-di-GMP) is a common bacterial second messenger that participates in the control of a variety of functions, including flagellar motility, biofilm formation, cell cycle, lifestyle transition, and virulence in pathogenic bacteria (Jenal et al. 2017; Römling and Simm 2009; Römling et al. 2005; Valentini and Filloux 2019). The synthesis and degradation of c-di-GMP are mediated by diguanylate cyclases (DGCs) and phosphodiesterases (PDEs), respectively. DGCs usually contain a conserved GGDEF domain, while PDEs typically have either an EAL domain or a HD-GYP domain (Bordeleau et al. 2011; Schirmer and Jenal 2009). Bacterial genomes usually encode a multitude of GGDEF, EAL, or HD-GYP domain proteins, many of which have been found in the genomes of diverse pathogenic bacteria (Römling et al. 2013). Cyclic di-GMP is sensed by a variety of receptors and effectors that control diverse cellular functions (Chou and Galperin 2016; Hengge 2009; Römling et al. 2013). Although many receptors or effectors, such as riboswitches, transcriptional regulators, PilZ domain proteins, GGDEF or EAL domain proteins, polynucleotide phosphorylases (PNPases), and kinases, have been shown to bind to c-di-GMP, it is likely that more receptors remain to be identified in bacteria (Chou and Galperin 2016).

Structural characterization and biological analysis have revealed that the RXXD motif of the I site in the GGDEF domain and the EXLXR motif in the EAL domain are crucial for c-di-GMP binding (Chou and Galperin 2016). Previous studies have indicated that degenerated GGDEF or EAL domain proteins without DGC or PDE activity, such as the 
histidine protein kinase SgmT in Myxococcus xanthus, with a degenerated GGDEF domain, and LapD in Pseudomonas fluorescens, with a degenerated EAL domain, serve as c-di-GMP receptors (Newell et al. 2009; Petters et al. 2012). In addition, the Xanthomonas FimX protein, which possesses degenerated GGDEF and EAL domains, has been shown to bind c-di-GMP specifically via its EAL domain (Guzzo et al. 2009; Navarro et al. 2009). In Xanthomonas axonopodis pv. citri, FimXxac interacts with the degenerated PilZ domain protein PilZ to regulate the bacterial type IV pilus biogenesis (Guzzo et al. 2009; Guzzo et al. 2013). This regulatory effect of FimXxac and PilZ on type IV pilus biogenesis is mediated mainly through the formation of a complex with the ATPase PilB, which is required for type IV pilus polymerization (Guzzo et al. 2009, 2013). Filp, which is a FimX homolog protein in $X$. oryzae pv. oryzae, has been shown to control not only sliding motility but also bacterial virulence by interacting with PilZX3 (PXO_02715) (Yang et al. 2014). These studies suggested that the FimX homolog proteins and its interactors may function via a common but difference regulatory pathway in Xanthomonas spp. In addition to the degenerated GGDEF and EAL domain proteins, some DGCs or PDEs perform diverse functions by converting between the active enzyme form and a receptor. Whitney et al. (2012) and Chan et al. (2004) reported that the DGC activity of PleD and WspR is allosterically inhibited by the binding of c-di-GMP via the I site of the GGDEF domain. In Escherichia coli, two trigger PDEs, PdeR and PdeL, have been identified as c-di-GMP-sensing effectors. PdeR (YciR) inhibits the expression of biofilm regulator $\mathrm{CsgD}$ by interacting with the DGC DgcM and the transcription factor MlrA at low c-diGMP levels. Interestingly, PdeR binds and degrades the c-diGMP signal molecule at high c-di-GMP levels, thereby releasing DgcM and MlrA to activate the expression of the csg DEFG operon (Hengge 2016).

Xanthomonas oryzae pv. oryzae is the causative pathogen of bacterial leaf blight in rice (Niño-Liu et al. 2006). Diverse virulence factors such as extracellular polysaccharide (EPS), extracellular cellulases and xylanases, yellow pigments and adhesion molecules, the type II secretion system (T2SS), T3SS and its effectors, contribute to the pathogenicity of $X$. oryzae $\mathrm{pv}$. oryzae in rice (Das et al. 2009; Kim et al. 2009; Rai et al. 2012). The expression of diverse virulence factors in $X$. oryzae pv. oryzae is controlled by c-di-GMP signaling (Yang et al. 2019). To date, several proteins involved in the production and sensing of c-di-GMP have been identified to regulate the virulence of $X$. oryzae pv. oryzae. Some of these members, including the GGDEF domain-containing DGCs GdpX1 and DgcA, the GGDEF and EAL domain-containing phosphodiesterase PdeR, the EAL domain-containing phosphodiesterase EdpX1, and the HD-GYP domain-containing phosphodiesterase RpfG, control the production of EPS, motility, biofilm formation, T3SS, and virulence of $X$. oryzae pv. oryzae by regulating the c-di-GMP concentration or through interactions with specific proteins (He et al. 2010; $\mathrm{Su}$ et al. 2016; Xue et al. 2018; Yang et al. 2012, 2016). The transcriptional regulator Clp, the degenerated GGDEF/EAL domain protein Filp, and the PilZ domain proteins PilZX1(PXO_00049) and PilZX2 (PXO_02374) were shown to function as c-di-GMP receptors participating in regulation of virulence in $X$. oryzae $\mathrm{pv}$. oryzae (Guan et al. 2009; Yang et al. 2014, 2015).

In this study, we investigated the mechanism by which Filp and PilZX3 coregulate virulence in $X$. oryzae pv. oryzae strains through relative and absolute quantitation (iTRAQ)-based quantitative proteomic analysis. We identified 157 DEPs as putative components regulated by Filp and PilZX3. The expression of selected DEPs was determined at the transcriptional and translational levels. The functions of selected DEPs in bacterial virulence were assessed by biochemical and genetic analyses. The results suggested a broader regulatory influence of Filp and PilZX3 and implicated some of the regulatory components mediated by Filp and PilZX3 as novel virulence factors for $X$. oryzae pv. oryzae.

\section{RESULTS}

Gene deletion analysis revealed coregulatory roles of filp and pilZXX3 in virulence on rice.

Previous studies have shown that the c-di-GMP receptor Filp and the interactor PilZX3 protein are required for the full virulence of $X$. oryzae pv. oryzae through single mutation analysis (Yang et al. 2014). To further elucidate the mechanism by which filp and pilZX3 regulate virulence, the double mutant $\triangle$ filp $\triangle$ pilZX3 was constructed. The PXO99 ${ }^{\mathrm{A}}$ cells and derived mutants were inoculated onto susceptible rice (Oryza sativa $\mathrm{L}$. cv. Nipponbare) plant leaves by the leaf-clipping method. The disease symptoms were recorded by photography, and the lesion lengths were measured at 14 days postinoculation. The $\triangle$ filp $\triangle p i l Z X 3$ double mutant caused less severe disease symptoms (Supplementary Fig. S1A) and shorter lesion lengths (Supplementary Fig. S1B) compared with the wild-type strain $(P<0.05)$. These effects were similar to those caused by the filp or pilZX3 single mutants (Supplementary Fig. S1A and B), which supports that idea that Filp and PilZX3 coregulate the virulence of $X$. oryzae pv. oryzae (Yang et al. 2014).

\section{Filp/PilZX3-regulon revealed by iTRAQ-based proteomic analysis.}

To identify novel proteins with a putative function in the virulence regulatory network mediated by Filp and PilZX3, we performed a quantitative iTRAQ-liquid chromatography tandem mass spectrometry (LC-MS/MS) proteomics analysis on the wild-type $\mathrm{PXO} 99^{\mathrm{A}}$ and filp or pilZX3 single and double mutants. For the proteomics analysis, three independent cultures of the wild-type control and mutant strains were prepared in M210 nutrient-rich medium, and cells were collected in the exponential growth phase. Proteins were extracted and were subjected to the iTRAQ-LC-MS/MS proteomic analysis. Three independent biological replicate experiments were performed to account for biological variation. Using a peptide false discovery rate $(\mathrm{FDR}) \leq 0.01$, we identified a total of 2,346 proteins representing approximately $51.2 \%$ of the 4,587 predicted proteins encoded by the $X$. oryzae pv. oryzae PXO99 ${ }^{\mathrm{A}}$ genome from a total of 28,403 peptides. The raw MS proteomics data have been deposited with the ProteomeXchange Consortium via the PRIDE partner repository under the dataset identifier PXD015734.

\section{Filp and PilZX3-mediated putative regulatory networks.}

Using a cutoff of a 1.5 -fold change in expression and a $P$ value $<0.05$, we identified 283 DEPs (134 upregulated and 149 downregulated) in $\triangle$ filp, 235 DEPs (90 upregulated and 146 downregulated) in $\triangle p i l Z X 3$, and 222 DEPs (84 upregulated and 138 downregulated) in $\triangle$ filp $\triangle p i l Z X 3$ compared with the wildtype PXO99 ${ }^{\mathrm{A}}$ (Fig. 1; Supplementary File S1). In total, 157 DEPs (55 upregulated DEPs and 102 downregulated) were identified in the $\triangle$ filp, $\triangle$ pilZX3, and $\triangle$ filp $\triangle p i l Z X 3$ mutants (Supplementary File S1). In addition, 101 DEPs were observed only in the $\triangle$ filp mutant, 25 DEPs were observed only in the pilZX3 mutant, and 14 DEPs were observed only in the filp/ pilZX3 double mutant (Fig. 1).

A total of 157 DEPs coregulated by Filp and PilZX3 were categorized into different functional groups of biological process, cellular component, and molecular function using gene ontology (GO) annotations in the UniProtKB database. The molecular functions of 157 DEPs were displayed mainly in catalytic activity (27\%) and binding function (20\%) categories 
(Fig. 2A). In the biological process category, DEPs involved in metabolic progress $(31 \%)$ and cellular progress $(26 \%)$ were the most highly represented, although other biological functions such as establishment of localization and pigmentation, biological regulation, and localization were also represented (Fig. $2 \mathrm{~A})$. Cells and cell parts accounted for $17.2 \%$ of the DEPs in the cellular component category (Fig. 2A). Kyoto Encyclopedia of Genes and Genomes (KEGG) pathway analysis revealed that the DEPs regulated by Filp and PilZX3 were involved in different signaling pathways, including metabolic pathways, biosynthesis of secondary metabolites, bacterial secretion systems, oxidative phosphorylation, bacterial chemotaxis, and twocomponent systems (TCS) (Fig. 2B). Among these, the histidine kinase (HK)-response regulator (RR) hybrid protein (HrrP) B2SMT1 in TCS, the type IV pilus-regulated proteins B2SVI4 and B2SVI3, and the TonB-dependent receptor B2SSR1 were significantly upregulated in all three mutants, while chemotaxis proteins B2SRN6 (designated EdpX2), B2SRN7 (designated CheW1) and B2SRN8, putative PDEs B2SW52 (designated HGdpX2) and B2SRN6, TonB-dependent receptor B2SWG3 (designated TdrX2), and HKs and RRs involved in TCS (B2SKU2, B2SRX4, B2SW53, HGdpX2, EdpX2) were significantly downregulated (Supplementary Fig. S3). Moreover, 17 proteins with varied expression levels in the $\triangle$ filp, $\triangle p i l Z X 3$, and $\triangle$ filp $\triangle$ pilZX3 mutants were implicated in bacterial T6SS, such as the type VI secretion ATPase (B2SI83, $c l p V)$ and the type VI protein secretion system components B2SRJ2 (imcF), B2SI89 (evpB), and B2SI85 (evpF).

In bacteria, diverse proteins can form complex networks with many interactions in different pathways. To better understand the regulatory mechanisms of filp and pilZX3, the potential protein network connections for DEPs regulated by Filp and PilZX was constructed using STRING. In total, 102 of the 157 DEPs of filp and pilZX3 were mapped, mainly to two functional networks (group I and group II) (Fig. 2C). A specific network in group I had at least eight "focus" DEPs surrounding filp or pilZX3: B2SVI4 (pilY1), B2SVP3 (fimV), B2SRN6 (PXO_04753, designated as EdpX2), B2SW52 (PXO_00476, designated as HGdpX2), B2SKU2 (PXO_02305), B2SW53 (PXO_00475), B2SRN7 (PXO_04752, designated as CheW1), and B2SRN8 (PXO_04751) (Fig. 2C). The networks of interest corresponded to c-di-GMP signal degradation, TCS, chemotaxis proteins and type IV pilus regulation. The DEPs implicated in bacterial T6SSs and some of the uncharacterized proteins formed a complex interactive network in group II (Fig. 2C).

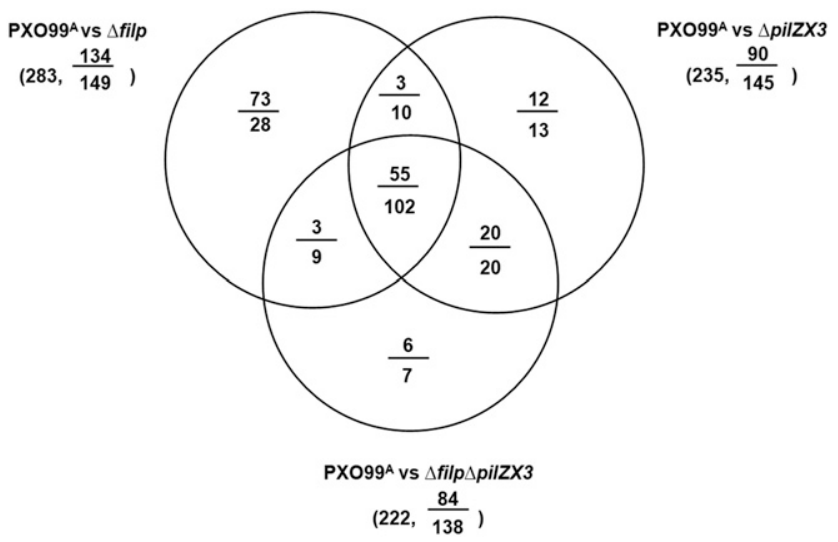

Fig. 1. Venn diagram showing the regulatory influence of filp and pilZX3. Data represent the number of proteins regulated by Filp or PilZX3. Numbers above and below lines indicate proteins that were upregulated and downregulated in filp, $\triangle$ pilZX3, or $\triangle$ filp $\triangle$ pilZX3 mutants, respectively.
Alteration in abundance of Filp/PilZX3-regulated proteins is associated with transcription.

To validate the reliability of iTRAQ data, seven candidate DEPs (HrrP, PhrP, ProP, CheW1, EdpX2, HGdpX2, and TdrX2) that represented different molecular functions were selected for further validation by Western blot analysis (Supplementary Fig. S3). As shown in Figure $3 \mathrm{~A}$ and B, the expression level of PhrP was significantly increased in the $\triangle p i l Z X 3$ and $\triangle$ filp $\triangle p i l Z X 3$ mutants but not in the $\Delta$ filp mutant compared with that in PXO99 ${ }^{\mathrm{A}}$. The expression of HrrP and ProP was significantly increased in mutants compared with that in the wild type, while the expression of CheW1, HGdpX2, and EdpX2 was decreased $(P<0.05)$ (Fig. 3A and B). Except for the expression of PhrP in the $\Delta$ filp mutant, the up-expression or down-expression trend of selected proteins were very similar to those shown by iTRAQ analyses (Fig. 3A and B), suggesting that the iTRAQ data were mostly reliable.

The altered abundance of proteins could be due to changes in transcriptional, translational, or post-translational regulation. The transcriptional levels of the DEPs were analyzed by quantitative reverse transcription-PCR (qRT-PCR) to determine their correlation with the changes in protein expression levels. Compared with the wild type, the mRNA levels of $h r r P, p h r P$, and proP were significantly increased in the $\triangle$ filp, $\triangle p i l Z X 3$, and $\triangle$ filp $\triangle$ pilZX3 mutants, while the mRNA levels of cheW1, $e d p X 2, h G d p X 2$, and $t d r X 2$ were significantly reduced $(P<$ 0.05 ) (Fig. 3B). These observations suggested that Filp and PilZX3 negatively regulate the expression of Hrrp, PhrP, and ProP and positively regulate the expression of CheW1, EdpX2, HGdpX2, and TdrX2 at both the transcriptional and translational levels.

\section{Novel components involved in Filp/PilZX3 regulation of virulence.}

To investigate the function of regulatory components mediated by Filp and PilZX3 on bacterial virulence in $X$. oryzae pv. oryzae, we constructed the deletion mutants and complemented strains for $h r r P$, phrP, proP, cheW1, edpX2, hGdpX2, and $t d r X 2$. The effects of these genes on $X$. oryzae pv. oryzae virulence were evaluated by inoculating susceptible rice plants (Oryza sativa subsp. japonica) with wild-type PXO99 ${ }^{\mathrm{A}}$, mutant, and complemented strains. The disease symptoms were scored 14 days postinoculation. Compared with the wild-type strain, $\Delta c h e W 1, \Delta h G d p X 2$, and $\Delta t d r X 2$ caused less severe disease symptoms (Fig. 4A) and shorter lesion lengths (Fig. 4B). In addition, $\triangle h r r P$ and $\triangle p r o P$ caused more severe disease symptoms and longer lesion lengths, while $\Delta e d p X 2$ and $\Delta p h r P$ did not obviously change the virulence of $X$. oryzae pv. oryzae (Fig. $4 \mathrm{~A}$ and $\mathrm{B})$. Complemented expression of the full-length genes in mutants resulted in almost complete restoration of the diseased phenotypes to that of the wild-type (Fig. 4A and B). This analysis revealed that the cheWl, hrrP, $h G d p X 2$, proP, and $t d r X 2$ genes identified by comparative proteomics analysis contributed to the regulation virulence in $X$. oryzae pv. oryzae.

\section{The regulatory components of Filp/PilZX3 influence the expression of virulence factors.}

Our results showed that the selected DEPs regulated by Filp/PilZX3 contributed to the virulence of $X$. oryzae pv. ory$z a e$; therefore, we investigated their influence on other virulence-related phenotypes, such as EPS production, motility, and biofilm formation. As shown in Supplementary Figure S4A, there was no significant difference between the wild type and mutants in terms of EPS secretion. Compared with wildtype PXO99 ${ }^{\mathrm{A}}$, the biofilm formation of $\Delta c h e W 1, \Delta e d p X 2$, and $\Delta t d r X 2$ mutants increased by approximately 55,38 , and $22 \%$, respectively. In contrast, there were no significant differences in 
biofilm formation between the $\triangle h G d p X 2, \Delta h r r P, \Delta p h r P$, and $\triangle$ proP mutants and wild-type PXO99 ${ }^{\mathrm{A}}$ (Supplementary Fig. S4B). Furthermore, $\triangle$ proP displayed increased sliding zones on SB media plates containing $0.6 \%$ agar while $\Delta e d p X 2$ displayed decreased sliding zones, indicating that proP and edpX2 regulate sliding motility of $X$. oryzae pv. oryzae (Supplementary Fig. S4C). In addition, the $\Delta h r r P$ strain showed a larger swimming zone than the wild-type $\mathrm{PXO}^{\mathrm{A}}$ on semisolid
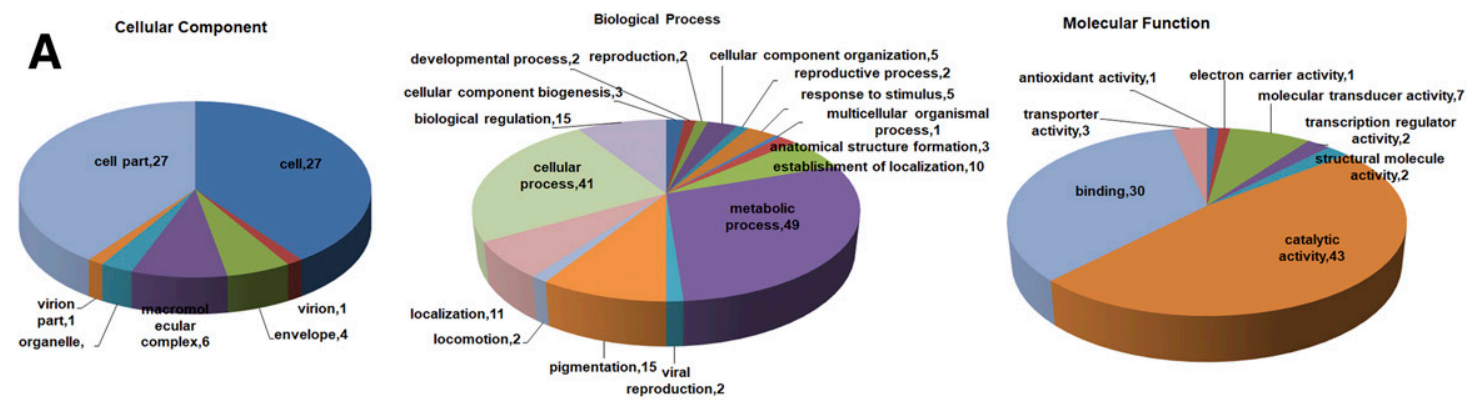

B
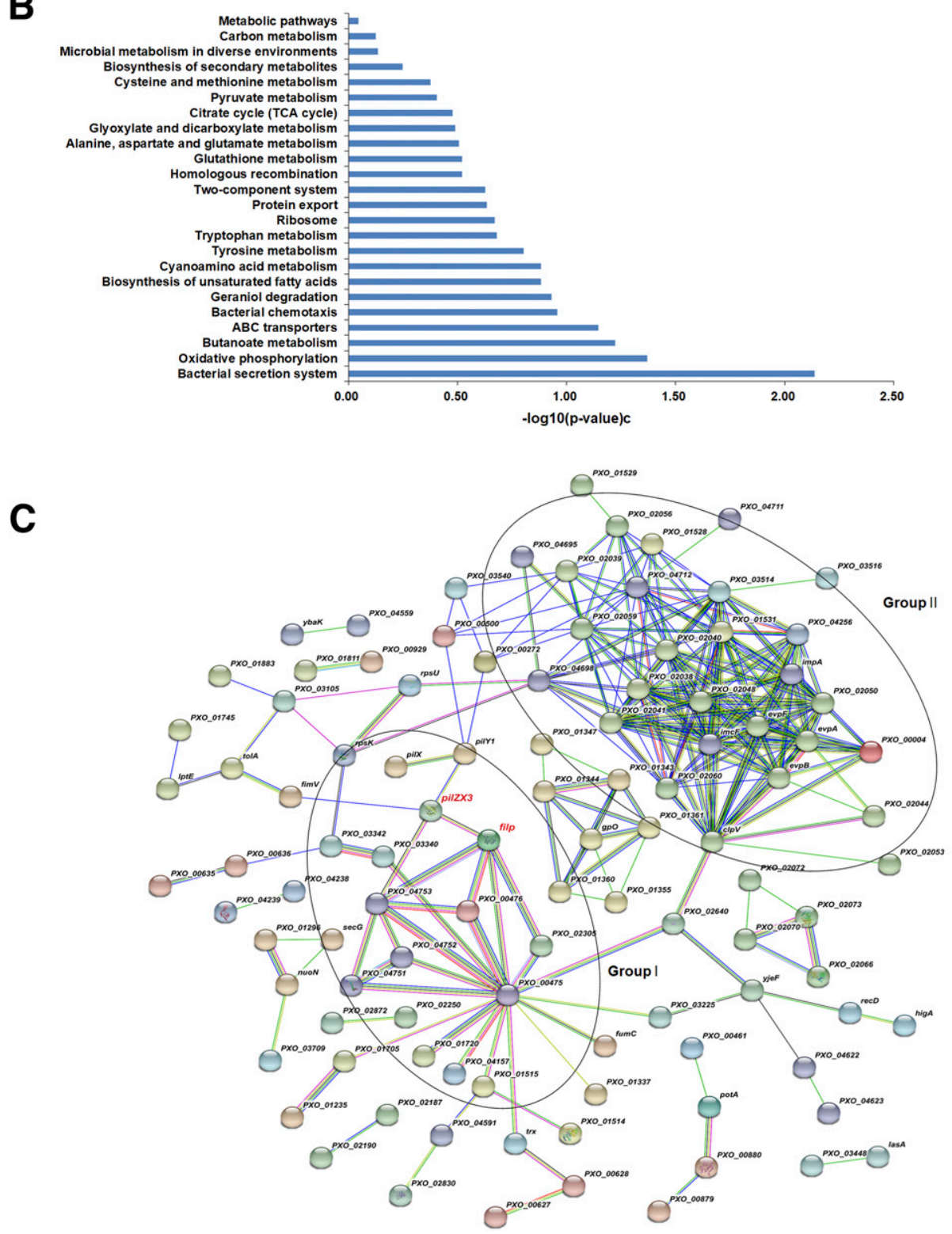

Fig. 2. The classification of differentially expressed proteins (DEPs) regulated by Filp and PilZX3. A, Gene ontology analyses of DEPs. B, Kyoto Encyclopedia of Genes and Genomes classification of DEPs. C, Specific network analysis of proteins coregulated by Filp and PilZX3 by STRING analysis. Each node represents a protein. Colored nodes indicate query proteins and the first shell of the interactor; white nodes indicate the second shell of the interactor. Filled nodes represent known or predicted three-dimensional structures. Lines represent the interaction between proteins. Green-blue (from the curated database) and pink (experimentally determined) lines indicate known interactions; green (gene neighborhood), red (gene fusions), and blue (gene co-occurrence) lines indicate predicted interactions; yellow (text mining), black (coexpression), and blue (protein homolog) lines represent other interactions. The width of the line indicates the proximity of the relationship. 
media plates containing $0.25 \%$ agar, whereas $\Delta c h e W 1$ and $\triangle h G d p X 2$ showed smaller swimming diameters (Supplementary Fig. S4D). These observations suggested that these targets of Filp and PilZX3 were also involved in the regulation of biofilm formation and motility but not EPS production of $X$. oryzae pv. oryzae.

\section{Both HGdpX2 and EdpX2 are PDEs active in c-di-GMP degradation.}

SMART program analysis indicated that HGdpX2 contains a HD-GYP domain and EdpX2 harbors an EAL domain (Supplementary Fig. S3), which are responsible for c-di-GMP degradation (Hengge 2009). To evaluate potential PDE activity of HGdpX2 and EdpX2, we first compared the intracellular cdi-GMP levels in wild-type PXO99 ${ }^{\mathrm{A}}$ and mutants by LCMS/MS. The results showed that the c-di-GMP concentration in $h G d p X 2$ and $e d p X 2$ mutants was increased by approximately 24 and $25 \%$ of the wild-type level, respectively, while the wild-type levels were restored in the complementary strains (Fig. 5A). Next, we tested the PDE activity of HGdpX2 and EdpX2 in vitro. In colorimetric assays, incubation of SUMO-His 6 -HGdpX2 and SUMO-His ${ }_{6}$-EdpX2 with bis ( $p$ nitrophenyl) phosphate overnight resulted in production of a significant amount of $p$-nitrophenol compared with that detected in the bovine serum albumin (BSA) control (Fig. 5B). Approximately 45 and $27 \%$ c-di-GMP were degraded by SUMO-His 6 -HGdpX2 and SUMO-His ${ }_{6}$-EdpX2, respectively, in the specified conditions, while no c-di-GMP degradation was observed in the BSA control (Fig. 5C). These results implied that $\mathrm{HGdpX} 2$ and $\mathrm{EdpX} 2$ were active PDEs in $X$. oryzae pv. oryzae.

\section{DISCUSSION}

C-di-GMP exerts diverse cellular functions at the transcriptional, translational, and post-translational levels (Chou and Galperin 2016; Hengge 2009; Römling et al. 2013). Previous studies have revealed that homologs of FimX and its interacting PilZ domain protein in Xanthomonas spp. participate in type IV pilus assembly and regulation of bacterial virulence (Guzzo et al. 2009, 2013; Yang et al. 2014). Although protein interaction analysis has provided insights into the regulatory influence of FimXac and PilZ on type IV pilus, little is known about the mechanism by which Filp and PilZX3 regulate virulence. In this study, we showed that mutation of filp and pilZX3 has a substantial effect on the $X$. oryzae pv. oryzae proteome, coaffecting the expression of 157 DEPs, including signal-sensing HKs and RRs in a TCS as well as PDEs and DGCs, chemotaxis proteins, TonB-dependent receptors, prophage proteins, and proteins involved in type IV pilus assembly or T6SSs. Thus, our findings provide further evidence that filp and pilZX3 are functionally related. Among these DEPs, HGdpX2, CheW1 and TdrX2 positively regulated the virulence of $X$. oryzae pv. oryzae, while HrrP and ProP negatively regulated virulence (Fig. 3A), suggesting that these proteins are novel virulence regulators of $X$. oryzae pv. oryzae and that they are mediated by Filp and PilZX3.

\section{Proteins involved in TCS, including two PDEs, were promoted by Filp and PilZX3.}

It has been generally recognized that TCS composed of a signal-sensing $\mathrm{HK}$ and a RR with a receiver domain regulate gene expression or bacterial cellular behavior under different

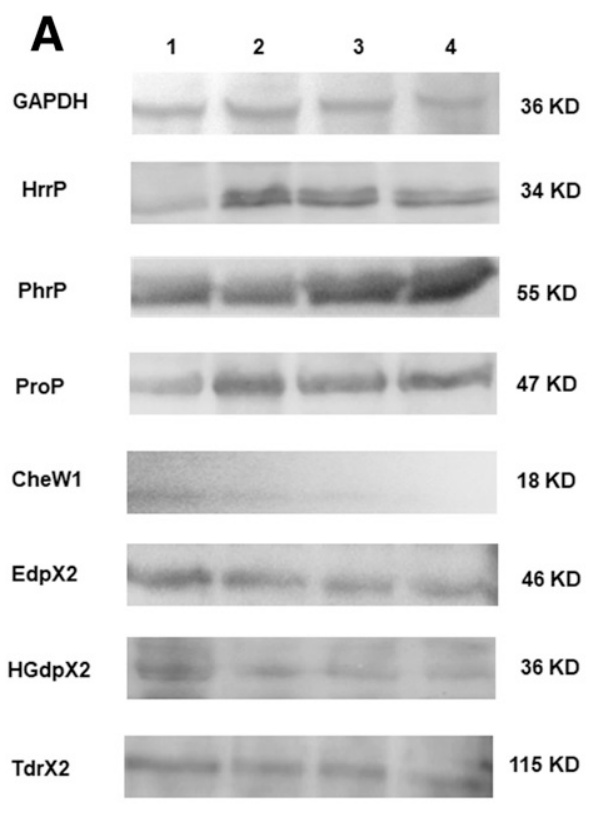

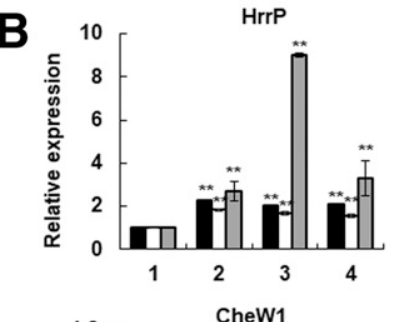
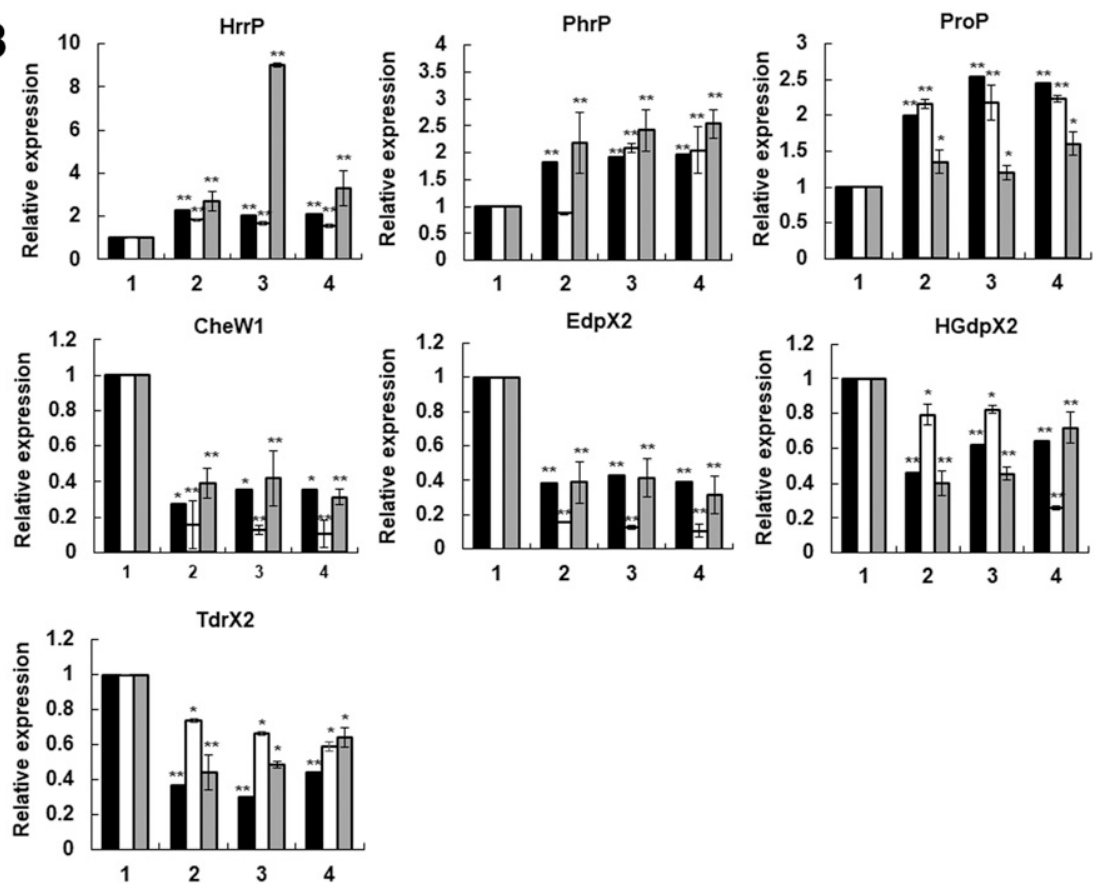

Fig. 3. Expression of selected differentially expressed proteins (DEPs) determined in various Xanthomonas oryzae pv. oryzae strains by Western blot and quantitative PCR analyses. A, Western blot analyses comparing expression of DEPs in wild-type PXO99 ${ }^{\mathrm{A}}, \Delta f i l p, \Delta$ pilZX3, and $\Delta$ filp $\Delta$ pilZX3 mutants. Samples containing $10 \mu \mathrm{g}$ of protein were loaded in each lane and were analyzed by immunoblotting with corresponding antibodies. Protein expression of the housekeeping gene GAPDH was used as a reference. All individual blots were repeated three times using samples from independent cultures. B, The black columns represent the expression levels of DEPs quantified by isobaric tagging for relative and absolute quantitation. The white columns represent the expression levels of DEPs determined by Western blot analysis and quantified using Image $\mathbf{J}$ software. The grayscale values of bands were quantified to calculate the relative ratios of DEPs. The relative grayscale value in the wild type was arbitrarily designated as 1 for each reaction. The gray columns represent the expression levels of DEP-encoding genes were detected by quantitative reverse transcription PCR analysis using the $2^{-\Delta \Delta \mathrm{Ct}}$ method. The housekeeping gene gyr $B$ was used as a reference. The expression level of each gene in the wild type was arbitrarily designated as 1 for each reaction. The experiment was repeated three times with similar results. $1=$ PXO99 $9^{\mathrm{A}}, 2=\Delta$ filp, $3=\Delta$ pilZX3, $4=\Delta$ filp $\Delta$ pilZX3. One asterisk $(*)$ indicates $P<0.05$, two $(* *)$ indicates $P<0.01$ by $t$ test. 
environmental conditions (Kulasekara et al. 2013). A large number of TCSs have been identified in the genome of Xanthomonas campestris pv. campestris (Qian et al. 2008). Although several proteins encoded by the $X$. oryzae pv. oryzae genome have been characterized as putative HKs or RRs, only a few have been experimentally confirmed (Lee et al. 2008).
Some of these proteins were found to be related to c-di-GMP metabolism, including the PDE PdeR with its cognate HK PdeK, the RR TriP and its PdeR interactor, and the HK RpfC with the PDE RpfG (He et al. 2010; Li et al. 2019; Yang et al. 2012, 2019). In this study, we showed that the expression of 11 putative components of TCS were regulated by Filp or PilZX3.

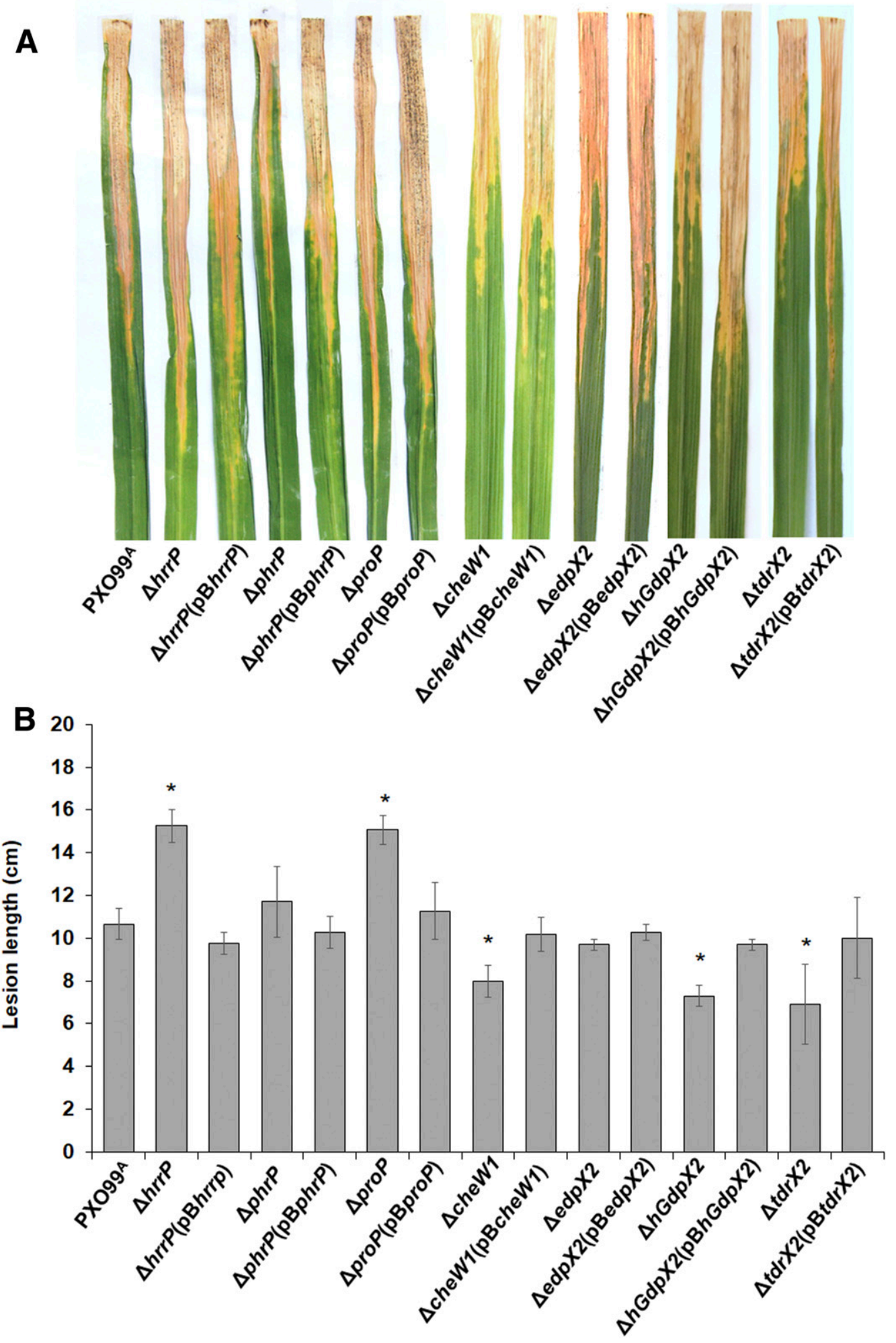

Fig. 4. Virulence test of mutant and complemented Xanthomonas oryzae pv. oryzae strains in rice. A, Rice plants were inoculated with X. oryzae pv. oryzae strains using the leaf-clipping method. The disease symptoms were observed 14 days after inoculation. B, Diseased lesion lengths were recorded. Data represent the mean \pm standard deviation of at least 10 leaves. Three independent experiments were performed with similar results. An asterisk $(*)$ indicates $P<0.05$ by $t$ test. 
Among them, three of six HKs or RRs that were coregulated by Filp and PilZX3 were identified in this study. The putative HKRR HrrP, which contains only a GAF signal-sensing domain, was shown to negatively regulate the virulence of $X$. oryzae $\mathrm{pv}$. oryzae. Interestingly, the RR HGdpX2 containing a HD-GYP domain and EdpX2 containing an EAL domain were identified as PDEs that promote bacterial virulence or biofilm formation by modulating the intracellular c-di-GMP concentration in $X$. oryzae pv. oryzae. Intracellular c-di-GMP concentrations in bacteria are controlled by DGCs and PDEs (Schirmer and Jenal 2009). Expression of HGdpX2 and EdpX2 was positively regulated by Filp and PilZX3, indicating the possible existence of a feedback mechanism of c-di-GMP regulated by Filp and PilZX3. Moreover, PcrR, the homolog of HGdpX2 from $X$. campestris pv. campestris, formed a novel TCS with its cognate HK PcrK (the homolog of PXO_00475) and was involved in virulence regulation by degrading c-di-GMP (Wang et al. 2017). Interestingly, we also found that HK PXO_00475, which is the homolog of PcrK from $X$. campestris pv. campestris, was positively regulated by Filp and PilZX3. The interaction network analysis revealed that PXO_00475 was in the center of the interaction network of group II, suggesting PXO_00475 might be an important component controlled by Filp and PilZX3.

\section{Proteins involved in the chemotaxis signaling pathway were upregulated by Filp and PilZX3.}

The chemotaxis signaling pathway, which is a well-characterized model of signal transduction, participates in the regulation of the bacterial swimming/twitching motility, biofilm formation, and virulence (Matilla and Krell 2018). The main molecular components of the chemotaxis signaling transduction pathway are highly conserved in bacteria, including transmembrane
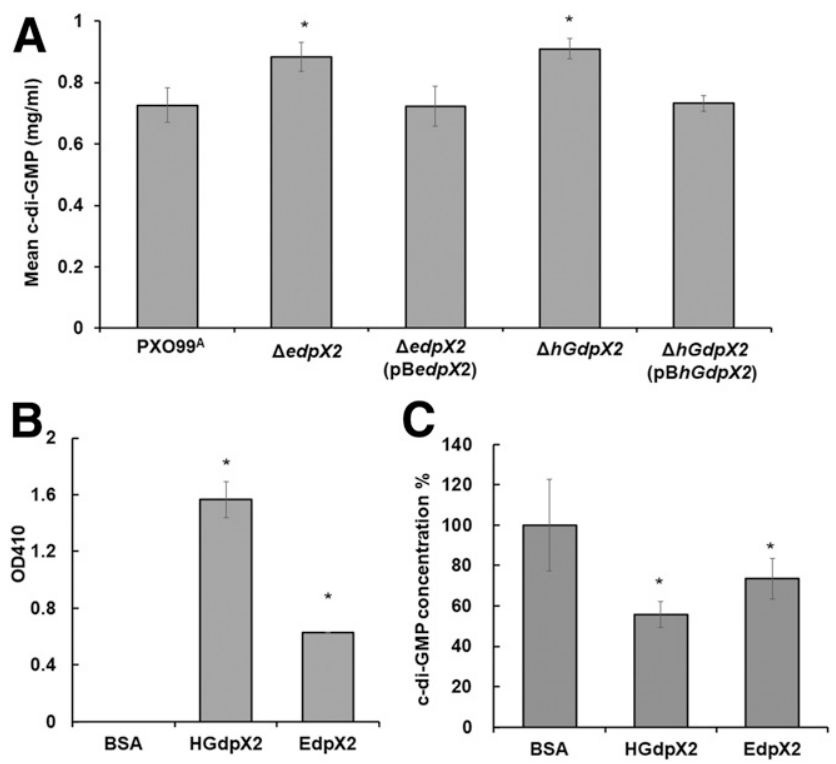

Fig. 5. Both HGdpX2 and EdpX2 function as phosphodiesterases (PDEs) in vivo and in vitro. A, Intracellular c-di-GMP was extracted from Xanthomonas oryzae pv. oryzae wild type, mutants, and complement strains and was measured by liquid chromatography tandem mass spectrometry (LCMS/MS). B, PDE activity of HGdpX2 and EdpX2 was tested by in vitro colorimetric assay. Purified recombinant EdpX2-His6 and HGdpX2-His6 proteins were incubated with $5 \mathrm{mM}$ bis-pNPP overnight at $37^{\circ} \mathrm{C}$. Degradation of bis-pNPP into pNP was detected at $410 \mathrm{~nm}$ by spectrophotometry. C, PDE activity of HGdpX2 and EdpX2 was analyzed by LC-MS/MS. Purified proteins were incubated overnight at $37^{\circ} \mathrm{C}$ with $100 \mathrm{mmol} \mathrm{c}$-diGMP. The products were analyzed by LC-MS/MS. An asterisk (*) indicates $P<0.05$ by $t$ test chemoreceptors, the cytoplasmic kinase CheA, the adaptor protein CheW, the RR CheY, the methytransferase CheR, and the methylesterase CheB (Wuichet and Zhulin 2010). The chemotaxis signaling pathway in $X$. oryzae pv. oryzae is remarkably complex, with at least four chemotaxis (che) gene clusters encoding the components (Kumar Verma et al. 2018). In this study, 11 putative components of the chemotaxis signaling transduction pathway were found to be regulated by Filp or PilZX3 (Supplementary Fig. S1). Among them, CheW1(B2SRN4), EdpX2(B2SRN6, VieA), CheB1 (B2SRN4), and MCP (B2SRN8) in the che1 gene cluster were coregulated by Filp and PilZX3. These results indicated a close connection between the chemotaxis signaling transduction pathway and Filp/PilZX3. Determination of the components of the chemotaxis signaling pathway in the $X$. oryzae pv. oryzae MAFF 311018 strain revealed that CheW1(XOO1468) positively regulates virulence, biofilm formation, and motility, while VieA (XOO1467) negatively regulates biofilm formation but positively regulates virulence (Kumar Verma et al. 2018). Deletion of CheB1 (XOO1469) decreased the virulence of X. oryzae pv. oryzae (Kumar Verma et al. 2018). CheW1, VieA, and CheB1 were required for the flagellar-mediated chemotactic response (Kumar Verma et al. 2018). In this study, we showed that CheW1 and EdpX2, which is the homolog of VieA in X. oryzae pv. oryzae MAFF 311018, were involved in the regulation of biofilm formation, motility, and virulence of the $X$. oryzae pv. oryzae PXO99 ${ }^{\mathrm{A}}$ strain. The regulatory effects of CheB1 and CheW1 on virulence were similar to those of Filp and PilZX3, which further supported the concept that the regulatory effects of these components are mediated via a similar pathway.

\section{The novel virulence factors of $X$. oryzae pv. oryzae were regulated by Filp and PilZX3.}

TonB-dependent receptors are outer membrane proteins that play important roles in the recognition of siderophores during iron uptake in gram-negative bacteria (Noinaj et al. 2010). Previous studies have revealed that some TonB-dependent receptors are involved in the regulation of bacterial virulence in Xanthomonas spp. For example, the TonB-dependent receptors XC4223, IroN, BfeA, and ButB are required for full virulence of $X$. campestris pv. campestris, while XCC3358 not only regulates the virulence of $X$. campestris pv. campestris in Arabidopsis but, also, the utilization of plant sucrose (Blanvillain et al. 2007; Qian et al. 2005). In X. oryzae pv. oryzae, TonB-dependent receptor TdrX1, which is the interactor of RR GacA, controls the bacterial growth, extracellular enzyme activity, motility, and virulence (Xu et al. 2010). Our data showed 11 TonB-dependent receptor/oar-like proteins were regulated by Filp or PilZX3, two of which were positively regulated. In this study, we also demonstrated that TdrX2 positively regulated virulence and negatively regulated biofilm formation. Therefore, we speculate that Filp and PilZX3 enhance nutrient uptake through upregulation of TonB-dependent receptors, thereby contributing to the virulence of $X$. oryzae pv. oryzae.

We also identified two components regulated by Filp and PilZX3, the PhoPQ-regulated protein PhrP and the prophage protein ProP, which negatively regulated the virulence and sliding motility of $X$. oryzae pv. oryzae. The TCS PhoPQ controls many pathogenic properties in several mammalian and plant pathogens (Moreira et al. 2015; Nakka et al. 2010). It is required for AvrXA21 activity, hrpG expressionand virulence of $X$. oryzae pv. oryzae (Lee et al. 2008). The mild phage integrates its DNA into the host genome to become prophages, with approximately $65 \%$ of bacterial genomes carrying prophage sequences. Prophage proteins play an important role in bacterial toxin synthesis and secretion, genome variation and evolution, environmental adaptability, and represent many bacterial virulence factors (Fortier and Sekulovic 2013; Varani 
et al. 2013; Zou et al. 2010). Interestingly, prophages contain riboswitches that are predicted to recognize c-di-GMP and are involved in multicellular behavior in Clostridium difficile (Fortier 2017). These findings suggested that these pathways are related to the c-di-GMP pathway that is regulated by Filp and PilZX3.

\section{Two important bacterial secretion systems might be influenced by Filp and PilZX3.}

Type IV pili, which are a widespread filamentous bacterial organelle, facilitate bacterial movement, adhesion, orientation, and multicellular organization (Mattick 2002). The extension, tethering, retraction, and extension of type IV pili is necessary for bacterial twitching/sliding motility. This organelle has garnered much attention in Xanthomonas spp. because type IV pili participate in pathogenesis, sliding/twitching motility, biofilm formation, and interactions with bacteriophages (Dunger et al. 2016). Our previous studies revealed that Filp interacted with PilZX3 to negatively regulate the sliding motility of $X$. oryzae pv. oryzae. In the present study, iTRAQ analysis showed that six proteins related to type IV pili assembly were markedly regulated by Filp or pilZX3, indicating that Filp and PilZX3 mediate sliding motility by regulating type IV pilus expression. PilX and PilY1 have been shown to be involved in the regulation of multiple bacterial biofunctions, including twitching motility in Xylella fastidiosa, virulence in Pseudomonas aeruginosa, and endothelial cell signaling in Neisseria meningitidi (Hélaine et al. 2005; Li et al. 2007; Marko et al. 2018). Mutation of PilY1 reduced the virulence in X. oryzae pv. oryzicola BLS303 (Wang et al. 2007). The expression of PilY1 and PilX were inhibited by Filp and PilZX3, suggesting that PilX and PilY1 might be involved in downstream regulators of sliding motility and virulence in $X$. oryzae pv. oryzae. FimX (the homolog of Filp), PilZ protein XAC1133 (the homolog of PilZX3), and ATPase PilB form a complex to promote the type IV pilus formation and inhibit sliding motility in X. axonopodis pv. citri (Guzzo et al. 2009, 2013; Qi et al. 2012). PilB (B2SSM0, the homolog of XAC1133), was downregulated in both the pilZX3 single mutant and the filp/ pilZX3 double mutant but not in the filp mutant, suggesting that PilB is regulated by pilZX3 alone. In addition, Filp acts independently to influence regulators of type IV pilus assembly, including the type IV pilus RR PilG (B2SSU9), the regulatory protein PilH family (B2SNJ7), and the type IV fimbriae assembly protein B2SNM9. PilG and PilH were an unlinked set of pil genes that were not in the pilus-regulated gene clusters. PilG was implicated in pilus extension and the role of PilH in regulating pilus retraction has been identified in Pseudomonas aeruginosa (Barken et al. 2008; Darzins and Russell 1997; Mattick et al. 1996). However, the contribution of PilG and PilH to virulence in Xanthomonas spp. remains unclear. Further identification of the biological roles of the type IV pilus in the virulence of $X$. oryzae pv. oryzae will help us understand the pathways regulated by Filp and PilZX3.

In addition, several proteins related to the T6SS were found to be regulated by Filp and PilZX in our iTRAQ analysis. The T6SS, a contact-dependent protein-secreting device that was first identified in Vibrio cholerae, injects a variety of effectors into eukaryotic and prokaryotic cells, thus playing important roles in bacterial interactions and virulence (Filloux et al. 2008; Pukatzki et al. 2009). T6SS is widely distributed in $25 \%$ of gram-negative bacteria with a highly conserved structure, including the 13 core components, a bacteriophage tail-like structure, and an injection system (Bernal et al. 2018). The c-diGMP signaling pathway has been shown to participate in T6SS biosynthesis in Pseudomonas spp. In Pseudomonas fluorescens, c-di-GMP binds specifically and with high affinity to the ATPase ClpB2 that is one of the core components of the T6SS (Trampari et al. 2015). In Pseudomonas aeruginosa, deletion of retS (encoding a sensor kinase) or overexpression of $w s p R$ (encoding a DGC) both lead to high intracellular levels of c-di-GMP, thereby upregulating the expression of T6SS. Inversely, overexpression of a PDE gene, PA2133, results in low c-di-GMP concentrations and inhibits the expression of T6SS (Moscoso et al. 2011). Studies have indicated that the c-di-GMP receptor FleQ and RopN cooperate to regulate the secretion of Hcp1 in T6SS at the transcriptional and post-transcriptional levels in Pseudomonas putida (Wang et al. 2018). T6SS is widespread in Xanthomonas spp., and the contribution of T6SS to bacterial competition but not virulence has been elucidated in X. oryzae pv. oryzicola (Ceseti et al. 2019; Zhu et al. 2019). The expression of several proteins related to T6SS that were upregulated by Filp and PilZX3 suggested that the c-di-GMP signaling pathway regulated by Filp and PilZX3 positively affects the expression of T6SS in $X$. oryzae pv. oryzae to allow the pathogen to gain a niche advantage during infection of rice.

A summary of the proteomic regulatory network of Filp and PilZX3 has been proposed (Fig. 6). The c-di-GMP receptor Filp and PilZX3 form a complex to regulate the virulence and sliding motility of $X$. oryzae pv. oryzae by promoting or suppressing signaling pathways, including TCS, the degradation of c-di-GMP, the chemotaxis signaling pathway, type IV pilus assembly, and the T6SS. In particular, crucial proteins in these signaling pathways and novel regulators that are regulated by Filp and PilZX3 contribute to the virulence of $X$. oryzae pv. oryzae in rice (Fig. 6). Overall, this study provides new insights into the mechanisms by which Filp and PilZX3 regulate virulence and provides insights into c-di-GMP signaling in $X$. oryzae pv. oryzae. T3SS and its effectors are the main virulence factors of $X$. oryzae pv. oryzae (White and Yang 2009). We have previously revealed that deletion of filp or pilZX3 in $X$. oryzae pv. oryzae led to a decrease in T3SS gene expression at the transcriptional level (Yang et al. 2014). However, the influences of Filp and PilZX3 on T3SS were not characterized at the translational level in this study due to use of nutrient-rich medium rather than the minimal medium that simulated in planta to induce T3SS gene expression (Furutanin et al. 2003). Further investigation of the mechanism by which Filp and PilZX3 regulate the virulence of $X$. oryzae pv. oryzae in planta will help reveal the roles of c-di-GMP signaling in the interaction between pathogens and plants.

\section{MATERIALS AND METHODS}

\section{Bacterial strains and growth conditions.}

The bacterial strains and plasmids used in this study are described in Table 1. E. coli cells were cultured at $37^{\circ} \mathrm{C}$ in Luria-Bertani (LB) medium (Hanahan 1983). The X. oryzae pv. oryzae wild-type strain $\mathrm{PXO} 99^{\mathrm{A}}$, mutants, and complementary strains were cultured at $28^{\circ} \mathrm{C}$ on peptone sucrose agar (PSA) medium or M210 liquid medium with appropriate antibiotics (Hopkins et al. 1992). Relevant antibiotics were used at the following concentrations: ampicillin, $100 \mu \mathrm{g} \mathrm{ml}^{-1}$; kanamycin, $50 \mu \mathrm{g} \mathrm{ml}^{-1}$; and gentamycin, $20 \mu \mathrm{g} \mathrm{ml}^{-1}$ (Wiśniewski et al. 2009).

\section{Construction of mutants and complementation.}

To generate in-frame gene deletions, the left and right fragments of pilZX3, hrrP, phrP, proP, cheW1, edpX2, hGdpX2, and $t d r X 2$ were amplified, using $X$. oryzae pv. oryzae genomic DNA as the template, with specific primers (Supplementary Table S1). The DNA fragments were inserted into the pKMS1 vector to generate plasmids pKMSpilZX3, pKMShrrP, pKMSphrP, 
pKMSproP, pKMScheW1, pKMShGdpX2, and pKMStdrX2. The plasmids were used to the delete target genes in the $X$. oryzae pv. oryzae genome through homologous recombination, as described previously (Zou et al. 2011). pKMSpilZX3 was electroporated into the filp mutant to generate the filp/pilZX3 double mutant. The pKMShrrP, pKMSphrP, pKMSproP, pKMScheW1, pKMShGdpX2, and pKMStdrX2 constructs were introduced into PXO99 ${ }^{\mathrm{A}}$ by electroporation. The potential mutants were screened as described by Zou et al. (2011). Single colonies that grew on PSA plates containing $10 \%$ sucrose but were sensitive to kanamycin were selected to validate the mutants by PCR. To generate the complemented strains, the coding region of $h r r P$, phrP, proP, che W1, $h G d p X 2$, and $t d r X 2$, including the ribosomal binding sites, were amplified using corresponding primer pairs (Supplementary Table S1). The PCR fragments were ligated into the pBBR1MCS-4 vector to generate the $\mathrm{pBhrr}$, $\mathrm{pB} p h r P$, $\mathrm{pB}$ proP, $\mathrm{pB} c h e W 1, \mathrm{pB} h G d p X 2$, and $\mathrm{pB} t d r X 2$ constructs, which were electroporated into the corresponding mutant strains for complementation analysis.

\section{iTRAQ analysis of the $X$. oryzae pv. oryzae proteome.}

Protein preparation and digestion. Previous studies have revealed that there are no differences in the growth characteristics of wild-type PXO99 $9^{\mathrm{A}}$ and the filp and pilZX3 single mutants (Yang et al. 2014). The same results were observed for the wild-type PXO99 ${ }^{\mathrm{A}}$ and the filp and pilZX3 double mutant (data not shown). The wild-type PXO99 ${ }^{\mathrm{A}}, \Delta$ filp, $\triangle p i l Z X 3$, and $\triangle$ filp $\triangle p i l Z X 3 X$. oryzae pv. oryzae strains were cultured to the exponential growth phase indicated by an optical density at $600 \mathrm{~nm}\left(\mathrm{OD}_{600}\right)$ of 0.8 . Briefly, $X$. oryzae pv. oryzae strains were cultured in M210 medium overnight at $28^{\circ} \mathrm{C}$ and were then transferred to $100 \mathrm{ml}$ of fresh M210 medium. The concentrations of bacteria were adjusted to $\mathrm{OD}_{600}=0.05$. These strains were then cultured at $28^{\circ} \mathrm{C}$ in a rotating incubator (200 rpm) for 12 to $24 \mathrm{~h}$. The $\mathrm{OD}_{600}$ of $X$. oryzae pv. oryzae strains was monitored until it reached 0.8 . Three biological replicates were prepared for each strain. Bacterial cells were collected and were washed twice with sterilized phosphate buffered saline (PBS). The cells were resuspended with HEPES buffer (20 mM HEPES, $9 \mathrm{M}$ urea, $\mathrm{pH}$ 8.0) and were mixed with quartz sand before bursts ( 10 times for $20 \mathrm{~s}$ ) of vigorous agitation at maximum speed, with incubation on ice for 5 min between each step. The samples were then lysed by bursts of ultrasonic treatment (power $80 \mathrm{~W}, 10$ times for $10 \mathrm{~s}$, interval time $15 \mathrm{~s}$ ) on ice. The supernatants were then collected by centrifugation at $13,400 \mathrm{rpm}$ for $30 \mathrm{~min}$ and the protein concentration was evaluated by the Bradford method (Tiangen). Equal amounts of proteins from each sample were digested with trypsin at $37^{\circ} \mathrm{C}$ for 16 to $18 \mathrm{~h}$, according to the method described by Wiśniewski et al. (2009), and finally, were lyophilized.

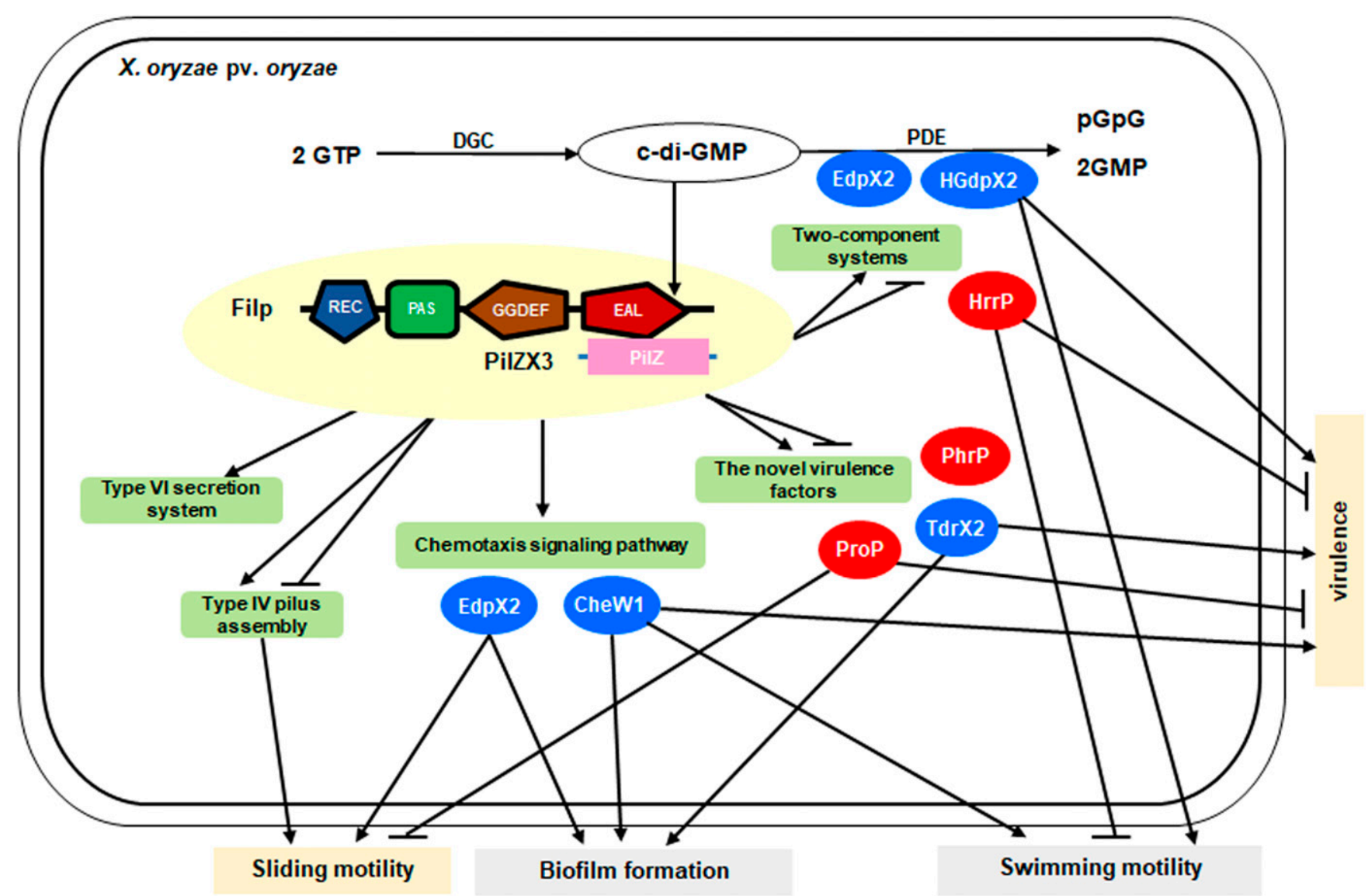

Fig. 6. A summary of the proteomic regulatory network of Filp and PilZX3 in Xanthomonas oryzae pv. oryzae. The degenerate GGDEF/EAL domain protein Filp binds to c-di-GMP through its EAL domain and interacts with the degenerate PilZ domain protein PilZX3 to regulate the sliding motility and virulence of $X$. oryzae pv. oryzae (Yang et al. 2014). Several important signaling pathways including two-component systems, degradation of c-di-GMP, the chemotaxis signaling pathway, type IV pilus assembly, and the type VI secretion system are regulated by Filp and PilZX3. The represented differentially expressed proteins (DEPs) CheW1, ProP, Hrrp, and HGdpX2 contribute to the virulence of X. oryzae pv. oryzae in rice. Besides the DEPs-related type IV pili assembly, EdpX2, ProP, and TdrX2 involve the regulation of sliding motility of $X$. oryzae pv. oryzae. In addition, CheW1, HrrP, EdpX2, and TdrX2 also affect the biofilm formation or swimming motility. The ovals filled in red and blue indicate the upregulated and downregulated DEPs in the $\Delta$ filp, $\Delta p i l Z X 3$, and $\Delta$ filp $\Delta p i l Z X 3$ mutants, respectively. Arrowheads at the end of lines represent positive regulated trends and bars at the end of lines indicate negative regulated trends. 
iTRAQ sample labeling and LC-MS/MS analysis. The protein labeling was carried out according to manufacturer instructions (AB Sciex). Four groups of proteins were labeled with the reporter tags $114\left(\mathrm{PXO}^{\mathrm{A}}\right), 116(\Delta$ filp $), 115(\Delta$ pilZX3), and 113 ( $\triangle$ filp $\triangle$ pilZX3), respectively. The iTRAQ-labeled peptides were separated by strong-cation exchange chromatography on the AKTA purifier system (GE Healthcare). The labeled peptides were fractionated and acidified before loading onto a polysulfoethyl column ( $5 \mu \mathrm{m}, 4.6 \times 100 \mathrm{~mm}$ column; PolyLC Inc.). The collected fractions were combined into five pools and were then desalted on C18 cartridges. The fractions were vacuum-centrifuged to dryness and were dissolved in $0.1 \%$ trifluoroacetic acid.

(MS/MS analysis was performed on a Q-extracted mass spectrometer (Thermo Fisher Scientific). For each fraction, peptide mixtures were injected into a C18-reversed phase highpressure liquid chromatography (HPLC) column $(3 \mu \mathrm{m}, 7.5 \times$ $100 \mathrm{~mm}$; Thermo Scientific Easy Column), were separated at a flow rate of $250 \mathrm{nl} / \mathrm{min}$ and a linear gradient of acetonitrile in buffer B (80\% acetonitrile and $0.1 \%$ formic acid) for $140 \mathrm{~min}$. A data-dependent top-10 method was used to acquire the MS data and select the most abundant precursor ions in the range of $\mathrm{m} / z, 300$ to 1,800 from the survey scan for HCD fragmentation. The target value was determined based on predictive automatic gain control and the dynamic exclusion duration was $60 \mathrm{~s}$. The parameters of the second level of MS were as follows: resolution of 17,500 at $\mathrm{m} / \mathrm{z}, 200,30 \mathrm{eV}$ of normalized collision energy, and $0.1 \%$ of the underfill rate.
Sequence database searching and data analysis. For quantification and identification of proteins, the MS/MS spectra were submitted to MASCOT (version 2.2; Matrix Science) using Proteome Discoverer 1.3 (Thermo Electron). The UniProt Xanthomonas oryzae pv. oryzae $\mathrm{PXO} 99^{\mathrm{A}}$ database $(133,549$ sequences, downloaded July 10, 2017) was used for the MS/MS data search. The FDR for peptides was set to 0.01 to filter the effective peptides. The proteins with a 1.5 -fold change in expression and a $P$ value $<0.05$ were considered as differentially expressed protein.

GO analyses were conducted using the GO database. The KEGG database was used to predict the metabolic pathway of the proteins. The functional associations between proteins were analyzed using the STRING database. A heatmap was created to show the expression level of proteins using the Pheatmap function in the $\mathrm{R}$ package (version 3.4.3) (Kolde 2015).

\section{Protein expression, purification, and antibody preparation.}

The DNA fragments encoding the $h r r P$, phrP, proP, cheWl, $e d p X 2, h G d p X 2$, and $t d r X 2$ genes were amplified using corresponding primer pairs (Supplementary Table S1). The fragments were cloned into pColdSUMO to generate the pCHrrP, pCPhrP, pCProP, pCCheW1, pCEdpX2, pCHGdpX2, and pCTdrX2 plasmids and were verified by sequencing. The plasmids were transformed into E. coli BL21 strains and the

Table 1. The bacterial strains and plasmids used in this study

\begin{tabular}{|c|c|c|}
\hline Strain or plasmid & Relevant characteristics $^{\mathbf{a}}$ & Reference or source \\
\hline \multicolumn{3}{|l|}{ Escherichia coli } \\
\hline $\mathrm{DH} 5 \alpha$ & $F^{-} \varphi 80($ lacZ $) \Delta$ lacX74hsdR $\left(r_{k}^{-}, m_{k}^{+}\right) \Delta r e c A 1398$ endA1tonA & TransGene Biotech, Beijing \\
\hline \multicolumn{3}{|c|}{ Xanthomonas oryzae pv. oryzae } \\
\hline PXO99A & Wild-type strain, Philippine race $6, \mathrm{Cp}^{\mathrm{r}}$ & Our laboratory \\
\hline$\Delta$ filp & filp gene deletion mutant derived from $\mathrm{PXO} 99^{\mathrm{A}}, \mathrm{Gm}^{\mathrm{r}}, \mathrm{Cp}^{\mathrm{r}}$ & Yang et al. 2014 \\
\hline$\Delta p i l Z X 3$ & pilZX3 gene deletion mutant derived from $\mathrm{PXO99}{ }^{\mathrm{A}}, \mathrm{Gm}^{\mathrm{r}}, \mathrm{Cp}^{\mathrm{r}}$ & Yang et al. 2014 \\
\hline$\Delta$ filp $\Delta$ pilZX3 & filp and pilZX3 gene double deletion mutant derived from $\mathrm{PXO} 99^{\mathrm{A}}, \mathrm{Gm}^{\mathrm{r}}, \mathrm{Cp}^{\mathrm{r}}$ & This study \\
\hline$\Delta h r r P$ & hrrP gene deletion mutant derived from $\mathrm{PXO} 99^{\mathrm{A}}, \mathrm{Cp}^{\mathrm{r}}$ & This study \\
\hline$\Delta p h r P$ & phrP gene deletion mutant derived from $\mathrm{PXO} 99^{\mathrm{A}}, \mathrm{Cp}^{\mathrm{r}}$ & This study \\
\hline$\Delta p r o P$ & proP gene deletion mutant derived from $\mathrm{PXO} 99^{\mathrm{A}}, \mathrm{Cp}^{\mathrm{r}}$ & This study \\
\hline$\Delta c h e W 1$ & cheW1 gene deletion mutant derived from PXO99 ${ }^{\mathrm{A}}, \mathrm{Cp}^{\mathrm{r}}$ & This study \\
\hline$\Delta e d p X 2$ & $e d p X 2$ gene deletion mutant derived from $\mathrm{PXO} 99^{\mathrm{A}}, \mathrm{Cp}^{\mathrm{r}}$ & This study \\
\hline$\Delta h G d p X 2$ & $h G d p X 2$ gene deletion mutant derived from $\mathrm{PXO} 99^{\mathrm{A}}, \mathrm{Cp}^{\mathrm{r}}$ & This study \\
\hline$\Delta t d r X 2$ & $\Delta t d r X 2$ gene deletion mutant derived from $\mathrm{PXO} 99^{\mathrm{A}}, \mathrm{Cp}^{\mathrm{r}}$ & This study \\
\hline \multicolumn{3}{|c|}{ 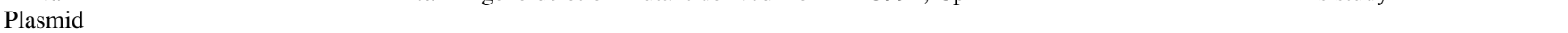 } \\
\hline pKMS1 & Suicidal vector carrying $s a c B$ gene for mutagenesis, $\mathrm{Km}^{\mathrm{r}}$ & (Schäfer et al. 1994) \\
\hline pBBR1MCS-4 & Broad-host range expression vector, $\mathrm{Ap}^{\mathrm{r}}$ & (Hopkins et al. 1992) \\
\hline pEASY-Blunt & Cloning vector, $\mathrm{Ap}^{\mathrm{r}}$ & TransGen Biotech \\
\hline pColdSUMO & Expression vector to generate a N-terminal SUMO-His ${ }_{6}$-tag, $\mathrm{Ap}^{\mathrm{r}}$ & Haigene \\
\hline pKMSPilZX3 & pKMS1 with pilZX3, $\mathrm{Km}^{\mathrm{r}}$ & This study \\
\hline pCHrrP & pColdSUMO containing the HrrP coding sequence, Ap ${ }^{r}$ & This study \\
\hline pCPhrP & pColdSUMO containing the PhrP coding sequence, $\mathrm{Ap}^{\mathrm{r}}$ & This study \\
\hline pCProP & pColdSUMO containing the ProP coding sequence, $\mathrm{Ap}^{\mathrm{r}}$ & This study \\
\hline pCCheW1 & pColdSUMO containing the CheW1 coding sequence, Ap ${ }^{r}$ & This study \\
\hline pCEdpX2 & pColdSUMO containing the EdpX2 coding sequence, $\mathrm{Ap}^{\mathrm{r}}$ & This study \\
\hline pCTdrX2 & pColdSUMO containing the TdrX2 coding sequence, $\mathrm{Ap}^{\mathrm{r}}$ & This study \\
\hline pKMShrrP & pKMS1 with $h r r P, \mathrm{Km}^{\mathrm{r}}$ & This study \\
\hline pKMSphrP & pKMS1 with $p h r P, \mathrm{Km}^{\mathrm{r}}$ & This study \\
\hline pKMSproP & pKMS1 with proP, $\mathrm{Km}^{\mathrm{r}}$ & This study \\
\hline pKMScheW1 & pKMS1 with cheW1, $\mathrm{Km}^{\mathrm{r}}$ & This study \\
\hline pKMSedpX2 & pKMS1 with $e d p X 2, \mathrm{Km}^{\mathrm{r}}$ & This study \\
\hline pKMStdrX2 & pKMS1 with $t d r X 2, \mathrm{Km}^{\mathrm{r}}$ & This study \\
\hline $\mathrm{pB} h r r P$ & pBBR1MCS-4 carrying the full-length of $h r r P, \mathrm{Ap}^{\mathrm{r}}$ & This study \\
\hline $\mathrm{pB} p h r P$ & pBBR1MCS-4 carrying the full-length of $p h r P, \mathrm{Ap}^{\mathrm{r}}$ & This study \\
\hline pBproP & pBBR1MCS-4 carrying the full-length of proP, $\mathrm{Ap}^{\mathrm{r}}$ & This study \\
\hline $\mathrm{pB}$ cheWl & pBBR1MCS-4 carrying the full-length of cheWl, $\mathrm{Ap}^{\mathrm{r}}$ & This study \\
\hline $\mathrm{pB} e d p X 2$ & pBBR1MCS-4 carrying the full-length of $e d p X 2, \mathrm{Ap}^{\mathrm{r}}$ & This study \\
\hline $\mathrm{pB} h G d p X 2$ & pBBR1MCS-4 carrying the full-length of $t d r X 2, \mathrm{Ap}^{\mathrm{r}}$ & This study \\
\hline $\mathrm{pB} t d r X 2$ & pBBR1MCS-4 carrying the full-length of $t d r X 2, \mathrm{Ap}^{\mathrm{r}}$ & This study \\
\hline
\end{tabular}

${ }^{\mathrm{a}} \mathrm{Km}^{\mathrm{r}}, \mathrm{Ap}^{\mathrm{r}}, \mathrm{Gm}^{\mathrm{r}}$, and $\mathrm{Cp}^{\mathrm{r}}$ indicate resistance to kanamycin, ampicillin, gentamicin, and chloramphenicol, respectively. 
expression of the target proteins was induced by addition of $0.5 \mathrm{mM}$ isopropyl- $\beta$-D-thiogalactoside, followed by incubation at $16^{\circ} \mathrm{C}$ for $12 \mathrm{~h}$. The protein was purified according to previously described methods (Yang et al. 2012, 2014). New Zealand white rabbits were immunized with $6 \mathrm{mg}$ of each recombinant protein to prepare the specific multiclonal antibodies (Wuhan GeneCreate Biological Co.), which were then identified by coimmunoprecipitation and Western blot analyses.

\section{Western blotting analysis.}

Bacterial strains were cultured in $\mathrm{M} 210$ medium at $28^{\circ} \mathrm{C}$ to $\mathrm{OD}_{600}$ of 1.0. The cells were collected by centrifugation and were washed twice with sterilized PBS. The proteins were then extracted using the Minute Kit (Invent Biotech). Eluted proteins were separated by sodium dodecyl sulfate-polyacrylamide gel electrophoresis (12\% gels) and were transferred onto membranes for immunoblotting with corresponding primary antibodies that were generated in this study. Goat antirabbit secondary antibodies conjugated with horseradish peroxidase were used to recognize the primary antibodies. The results were visualized by addition the diaminobenzidine substrate (Tiangen Biotech)

\section{qRT-PCR analysis.}

Bacterial cells were collected after culture in $\mathrm{M} 210$ at $28^{\circ} \mathrm{C}$ to an $\mathrm{OD}_{600}$ of 0.8 . Total RNA was extracted using the RNAprep pure cell/bacteria kit (Tiangen). qPCRs were conducted using AceQ qPCR SYBR Green Master Mix (Vazyme) according to manufacturer instructions. The $\operatorname{gyr} B$ gene was used as an endogenous control for data normalization. The relative expression of each gene was calculated using the $2^{-\Delta \Delta C t}$ method (Livak and Schmittgen 2001). Three biological replicates were tested for each sample, with three technical replicates in each experiment. Details of the gene-specific primers are listed in Supplementary Table S1.

\section{Virulence test.}

Virulence was assessed in pathogenicity assays on susceptible rice plants (Oryza sativa L. cv. Nipponbare) following inoculation using the leaf-clipping method (Yang et al. 2012). The $X$. oryzae pv. oryzae strains were grown in M210 media at $28^{\circ} \mathrm{C}$ to an $\mathrm{OD}_{600}$ of 1.0 . The bacterial cells were resuspended in an equal volume of sterile distilled water, then, were inoculated onto rice leaves. Photos were taken and lesion lengths were measured at 14 days after inoculation. The experiments were repeated at least three times.

\section{Motility assay.}

Fresh $X$. oryzae pv. oryzae colonies were stabbed into semisolid plates containing $0.03 \%$ agar (Shen et al. 2001), for evaluation of swimming motility, and SB plates containing $0.5 \%$ (wt/vol) Bacto peptone, $0.5 \%$ yeast extract, $0.1 \%$ L-glutamic acid, $0.5 \%$ sugar, $\mathrm{pH} 7.0$, and $0.6 \%$ agar $0.6 \%$ agar (McCarthy et al. 2008), for evaluation of sliding motility. The plates were inoculated at $28^{\circ} \mathrm{C}$ for 4 days. The diameters of the swimming and sliding motility zones were measured in millimeters. This assay was repeated at least three times.

\section{EPS production assay.}

EPS production by $X$. oryzae pv. oryzae strains was quantified using the ethanol precipitation method (Tang et al. 1996). $X$. oryzae pv. oryzae strains were grown in M210 medium for $48 \mathrm{~h}$. The culture supernatants were then mixed with two volumes of absolute ethanol and were stored overnight at $20^{\circ} \mathrm{C}$. EPS molecules were collected by centrifugation at $12,000 \times g$ for $20 \mathrm{~min}$, were dried overnight at $55^{\circ} \mathrm{C}$, and were weighed. The experiment was independently repeated three times.

\section{Biofilm formation assay.}

Bacteria in the logarithmic growth phase were diluted in M210 medium to an $\mathrm{OD}_{600}$ of 0.5. Bacteria were incubated at $28^{\circ} \mathrm{C}$ for 4 days. Bacterial pellicles were stained with $0.1 \%$ crystal violet for $15 \mathrm{~min}$ at room temperature, then, were gently rinsed three times with distilled water. Biofilm formation was quantified by dissolving the adherent dye with ethanol and measuring the absorbance at $490 \mathrm{~nm}$ (An et al. 2010).

\section{Quantification of the intracellular c-di-GMP levels in $X$. oryzae pv. oryzae strains.}

The c-di-GMP in bacteria was extracted and quantified as previously described (Xue et al. 2018). X. oryzae pv. oryzae strains were cultured at $28^{\circ} \mathrm{C}$ in $200 \mathrm{ml}$ of M210 medium to $\mathrm{OD}_{600}$ of 2.0. The bacterial cells were collected by centrifugation at $12,000 \times g$ for 20 min and were resuspended in $1.5 \mathrm{ml}$ of extraction buffer ( $40 \%$ methanol, $40 \%$ acetonitrile). The mixtures were sonicated for $10 \mathrm{~min}$, following incubation on ice for $15 \mathrm{~min}$. After heating for $10 \mathrm{~min}$ at $95^{\circ} \mathrm{C}$, the suspension was collected by centrifugation at $13,000 \times g$ for $20 \mathrm{~min}$. The suspension was dried and dissolved with $100 \mu \mathrm{l}$ of HPLC-grade water. Then, $10 \mu \mathrm{l}$ of each sample was analyzed on an Agilent 1290 (Agilent) liquid chromatography system equipped with a QQQ (Agilent 6460) tandem mass spectrometer. Commercially synthesized c-di-GMP (Biolog) was used as a reference for quantification of c-di-GMP.

PDE activity analysis.

PDE activity of proteins was analyzed by colorimetric assay and LC-MS/MS analysis as previously described (Yang et al. 2012; Yi et al. 2010). For colorimetric assays, the reaction system containing $100 \mu \mathrm{g}$ of purified protein and $5 \mathrm{mM}$ bis ( $p$ nitrophenyl) phosphate in reaction buffer $(50 \mathrm{mM}$ Tris- $\mathrm{HCl}$, $1 \mathrm{mM} \mathrm{MnCl} 2, \mathrm{pH} \mathrm{8.5)}$ was incubated at $37^{\circ} \mathrm{C}$ for $2 \mathrm{~h}$. The yellow product ( $p$-nitrophenyl) was detected by measuring the $\mathrm{OD}_{410} \mathrm{~nm}$. In addition, $100 \mu \mathrm{g}$ of purified proteins were incubated with $10 \mu \mathrm{M}$ c-di- GMP in $1 \mathrm{ml}$ of reaction buffer (50 mM Tris- $\mathrm{mCl}, \mathrm{pH} 7.6,10 \mathrm{mM} \mathrm{MgCl} 2,10 \mathrm{mM} \mathrm{MnCl}_{2}$, $0.5 \mathrm{mM}$ EDTA, and $50 \mathrm{mM} \mathrm{NaCl}$ ) overnight at $37^{\circ} \mathrm{C}$. BSA was used as a negative control. The products were then measured by reverse phase-coupled LC-MS/MS analysis (Xue et al. 2018).

\section{ACKNOWLEDGMENTS}

We thank C. He for modifying the manuscript. We thank W. Wang at the Center of Biomedical Analysis, Tsinghua University for help with the LCMS/MS analysis.

\section{AUTHOR-RECOMMENDED INTERNET RESOURCES}

Gene Ontology database: http://geneontology.org

Kyoto Encyclopedia of Genes and Genomes (KEGG) database: https://www.genome.jp/kegg

Cran R Pheatmap function: cran.r-project.org/web/packages/pheatmap/index.html The ProteomeXchange Consortium: http://proteomecentral.proteomexchange.org STRING database: https://string-db.org

The UniProtKB database: https://www.uniprot.org

\section{LITERATURE CITED}

An, S., Wu, J., and Zhang, L. H. 2010. Modulation of Pseudomonas aeruginosa biofilm dispersal by a cyclic-Di-GMP phosphodiesterase with a putative hypoxia-sensing domain. Appl. Environ. Microbiol. 76: 8160-8173

Barken, K. B., Pamp, S. J., Yang, L., Gjermansen, M., Bertrand, J. J., Klausen, M., Givskov, M., Whitchurch, C. B., Engel, J. N., and TolkerNielsen, T. 2008. Roles of type IV pili, flagellum-mediated motility and extracellular DNA in the formation of mature multicellular structures in Pseudomonas aeruginosa biofilms. Environ. Microbiol. 10:2331-2343. 
Bernal, P., Llamas, M. A., and Filloux, A. 2018. Type VI secretion systems in plant-associated bacteria. Environ. Microbiol. 20:1-15.

Blanvillain, S., Meyer, D., Boulanger, A., Lautier, M., Guynet, C., Denancé, N., Vasse, J., Lauber, E., and Arlat, M. 2007. Plant carbohydrate scavenging through tonB-dependent receptors: A feature shared by phytopathogenic and aquatic bacteria. PLoS One 2:e224.

Bordeleau, E., Fortier, L. C., Malouin, F., and Burrus, V. 2011. c-di-GMP turn-over in Clostridium difficile is controlled by a plethora of diguanylate cyclases and phosphodiesterases. PLoS Genet. 7:e1002039.

Ceseti, L. M., de Santana, E. S., Ratagami, C. Y., Barreiros, Y., Lima, L. D. P., Dunger, G., Farah, C. S., and Alvarez-Martinez, C. E. 2019. The Xanthomonas citri pv. citri Type VI Secretion System is Induced During Epiphytic Colonization of Citrus. Curr. Microbiol. 76:1105-1111.

Chan, C., Paul, R., Samoray, D., Amiot, N. C., Giese, B., Jenal, U., and Schirmer, T. 2004. Structural basis of activity and allosteric control of diguanylate cyclase. Proc. Natl. Acad. Sci. U.S.A. 101:17084-17089.

Chou, S. H., and Galperin, M. Y. 2016. Diversity of Cyclic Di-GMPBinding Proteins and Mechanisms. J. Bacteriol. 198:32-46.

Darzins, A., and Russell, M. A. 1997. Molecular genetic analysis of type-4 pilus biogenesis and twitching motility using Pseudomonas aeruginosa as a model system--a review. Gene 192:109-115.

Das, A., Rangaraj, N., and Sonti, R. V. 2009. Multiple adhesin-like functions of Xanthomonas oryzae pv. oryzae are involved in promoting leaf attachment, entry, and virulence on rice. Mol. Plant-Microbe Interact 22:73-85.

Dunger, G., Llontop, E., Guzzo, C. R., and Farah, C. S. 2016. The Xanthomonas type IV pilus. Curr. Opin. Microbiol. 30:88-97.

Filloux, A., Hachani, A., and Bleves, S. 2008. The bacterial type VI secretion machine: Yet another player for protein transport across membranes. Microbiology 154:1570-1583.

Fortier, L. C. 2017. The Contribution of Bacteriophages to the Biology and Virulence of Pathogenic Clostridia. Adv. Appl. Microbiol. 101:169-200.

Fortier, L. C., and Sekulovic, O. 2013. Importance of prophages to evolution and virulence of bacterial pathogens. Virulence 4:354-365.

Furutani, A., Tsuge, S., Oku, T., Tsuno, K., Inoue, Y., Ochiai, H., Kaku, H., and Kubo, Y. 2003. Hpal secretion via type III secretion system in Xanthomonas oryzae pv. oryzae. J. Gen. Plant Pathol. 69:271-275.

Guan, W., Wu, M., and He, C. 2009. [Molecular identification and functional analysis of Clpxoo, a homologue to the nucleotide receptor protein in Xanthomonas oryzae pv. oryzae.]. Wei Sheng Wu Xue Bao 49:32-37.

Guzzo, C. R., Dunger, G., Salinas, R. K., and Farah, C. S. 2013. Structure of the PilZ-FimXEAL-c-di-GMP Complex Responsible for the Regulation of Bacterial Type IV Pilus Biogenesis. J. Mol. Biol. 425:2174-2197.

Guzzo, C. R., Salinas, R. K., Andrade, M. O., and Farah, C. S. 2009. PILZ protein structure and interactions with PILB and the FIMX EAL domain: Implications for control of type IV pilus biogenesis. J. Mol. Biol. 393: 848-866.

Hanahan, D. 1983. Studies on transformation of Escherichia coli with plasmids. J. Mol. Biol. 166:557-580.

He, Y. W., Wu, J., Cha, J. S., and Zhang, L. H. 2010. Rice bacterial blight pathogen Xanthomonas oryzae pv. oryzae produces multiple DSF-family signals in regulation of virulence factor production. BMC Microbiol. 10: 187.

Hélaine, S., Carbonnelle, E., Prouvensier, L., Beretti, J.-L., Nassif, X., and Pelicic, V. 2005. PilX, a pilus-associated protein essential for bacterial aggregation, is a key to pilus-facilitated attachment of Neisseria meningitidis to human cells. Mol. Microbiol. 55:65-77.

Hengge, R. 2009. Principles of c-di-GMP signalling in bacteria. Nat. Rev. Microbiol. 7:263-273.

Hengge, R. 2016. Trigger phosphodiesterases as a novel class of c-di-GMP effector proteins. Philos. Trans. R. Soc. Lond. B Biol. Sci. 371: 20150498.

Hopkins, C. M., White, F. F., Choi, S. H., Guo, A., and Leach, J. E. 1992. Identification of a family of avirulence genes from Xanthomonas oryzae pv. oryzae. Mol. Plant-Microbe Interact 5:451-459.

Jenal, U., Reinders, A., and Lori, C. 2017. Cyclic di-GMP: Second messenger extraordinaire. Nat. Rev. Microbiol. 15:271-284.

Kim, S. Y., Kim, J. G., Lee, B. M., and Cho, J. Y. 2009. Mutational analysis of the gum gene cluster required for xanthan biosynthesis in Xanthomonas oryzae pv oryzae. Biotechnol. Lett. 31:265-270.

Kolde, R. 2015. Package 'pheatmap.' R Package. The R Project for Statistical Computing.

Kulasekara, B. R., Kamischke, C., Kulasekara, H. D., Christen, M., Wiggins, P. A., and Miller, S. I. 2013. c-di-GMP heterogeneity is generated by the chemotaxis machinery to regulate flagellar motility. eLife 2:e01402.

Kumar Verma, R., Samal, B., and Chatterjee, S. 2018. Xanthomonas oryzae pv. oryzae chemotaxis components and chemoreceptor Mcp2 are involved in the sensing of constituents of xylem sap and contribute to the regulation of virulence-associated functions and entry into rice. Mol. Plant Pathol. 19:2397-2415.

Lee, S. W., Jeong, K. S., Han, S. W., Lee, S. E., Phee, B. K., Hahn, T. R., and Ronald, P. 2008. The Xanthomonas oryzae pv. oryzae PhoPQ twocomponent system is required for AvrXA21 activity, hrpG expression, and virulence. J. Bacteriol. 190:2183-2197.

Li, H., Xue, D., Tian, F., Yuan, X., Yang, F., Chen, H., Hutchins, W., Yang, C. H., and He, C. 2019. Xanthomonas oryzae pv. oryzae response regulator TriP regulates virulence and exopolysaccharide production via interacting with c-di-GMP phosphodiesterase PdeR. Mol. Plant-Microbe Interact 32:729-739.

Li, Y., Hao, G., Galvani, C. D., Meng, Y., Fuente, L., Hoch, H. C., and Burr, T. J. 2007. Type I and type IV pili of Xylella fastidiosa affect twitching motility, biofilm formation and cell-cell aggregation. Microbiology 153: 719-726.

Livak, K. J., and Schmittgen, T. D. 2001. Analysis of relative gene expression data using real-time quantitative PCR and the $2(-\Delta \Delta \mathrm{C}(\mathrm{T}))$ Method. Methods 25:402-408.

Marko, V. A., Kilmury, S. L. N., MacNeil, L. T., and Burrows, L. L. 2018 Pseudomonas aeruginosa type IV minor pilins and PilY1 regulate virulence by modulating FimS-AlgR activity. PLoS Pathog. 14: e1007074.

Matilla, M. A., and Krell, T. 2018. The effect of bacterial chemotaxis on host infection and pathogenicity. FEMS Microbiol. Rev. 42:fux052.

Mattick, J. S. 2002. Type IV pili and twitching motility. Annu. Rev. Microbiol. 56:289-314.

Mattick, J. S., Whitchurch, C. B., and Alm, R. A. 1996. The molecular genetics of type-4 fimbriae in Pseudomonas aeruginosa--a review. Gene 179:147-155.

McCarthy, Y., Ryan, R. P., O’Donovan, K., He, Y. Q., Jiang, B. L., Feng, J. X., Tang, J. L., and Dow, J. M. 2008. The role of PilZ domain proteins in the virulence of Xanthomonas campestris pv. campestris. Mol. Plant Pathol. 9:819-824.

Moreira, L. M., Facincani, A. P., Ferreira, C. B., Ferreira, R. M., Ferro, M. I. T., Gozzo, F. C., de Oliveira, J. C., Ferro, J. A., and Soares, M. R. 2015. Chemotactic signal transduction and phosphate metabolism as adaptive strategies during citrus canker induction by Xanthomonas citri. Funct. Integr. Genomics 15:197-210.

Moscoso, J. A., Mikkelsen, H., Heeb, S., Williams, P., and Filloux, A. 2011. The Pseudomonas aeruginosa sensor RetS switches type III and type VI secretion via c-di-GMP signalling. Environ. Microbiol. 13:3128-3138.

Nakka, S., Qi, M., and Zhao, Y. 2010. The Erwinia amylovora PhoPQ system is involved in resistance to antimicrobial peptide and suppresses gene expression of two novel type III secretion systems. Microbiol. Res. 165:665-673.

Navarro, M. V. A. S., De, N., Bae, N., Wang, Q., and Sondermann, H. 2009. Structural analysis of the GGDEF-EAL domain-containing c-di-GMP receptor FimX. Structure 17:1104-1116.

Newell, P. D., Monds, R. D., and O'Toole, G. A. 2009. LapD is a bis- $\left(3^{\prime}, 5^{\prime}\right)-$ cyclic dimeric GMP-binding protein that regulates surface attachment by Pseudomonas fluorescens Pf0-1. Proc. Natl. Acad. Sci. U.S.A. 106: 3461-3466.

Niño-Liu, D. O., Ronald, P. C., and Bogdanove, A. J. 2006. Xanthomonas oryzae pathovars: Model pathogens of a model crop. Mol. Plant Pathol. 7:303-324.

Noinaj, N., Guillier, M., Barnard, T. J., and Buchanan, S. K. 2010. TonBdependent transporters: Regulation, structure, and function. Annu. Rev. Microbiol. 64:43-60.

Petters, T., Zhang, X., Nesper, J., Treuner-Lange, A., Gomez-Santos, N., Hoppert, M., Jenal, U., and Søgaard-Andersen, L. 2012. The orphan histidine protein kinase SgmT is a c-di-GMP receptor and regulates composition of the extracellular matrix together with the orphan DNA binding response regulator DigR in Myxococcus xanthus. Mol. Microbiol. 84:147-165

Pukatzki, S., McAuley, S. B., and Miyata, S. T. 2009. The type VI secretion system: Translocation of effectors and effector-domains. Curr. Opin. Microbiol. 12:11-17.

Qi, Y., Xu, L., Dong, X., Yau, Y. H., Ho, C. L., Koh, S. L., Shochat, S. G., Chou, S. H., Tang, K., and Liang, Z. X. 2012. Functional divergence of FimX in PilZ binding and type IV pilus regulation. J. Bacteriol. 194: 5922-5931.

Qian, W., Han, Z. J., Tao, J., and He, C. 2008. Genome-scale mutagenesis and phenotypic characterization of two-component signal transduction systems in Xanthomonas campestris pv. campestris ATCC 33913. Mol. Plant-Microbe Interact 21:1128-1138.

Qian, W., Jia, Y., Ren, S.-X., He, Y. Q., Feng, J. X., Lu, L. F., Sun, Q., Ying, G., Tang, D. J., Tang, H., Wu, W., Hao, P., Wang, L., Jiang, B. L., Zeng, 
S., Gu, W. Y., Lu, G., Rong, L., Tian, Y., Yao, Z., Fu, G., Chen, B., Fang, R., Qiang, B., Chen, Z., Zhao, G. P., Tang, J. L., and He, C. 2005. Comparative and functional genomic analyses of the pathogenicity of phytopathogen Xanthomonas campestris pv. campestris. Genome Res. 15:757-767.

Rai, R., Ranjan, M., Pradhan, B. B., and Chatterjee, S. 2012. Atypical regulation of virulence-associated functions by a diffusible signal factor in Xanthomonas oryzae pv. oryzae. Mol. Plant-Microbe Interact 25:789-801.

Römling, U., Galperin, M. Y., and Gomelsky, M. 2013. Cyclic di-GMP: The first 25 years of a universal bacterial second messenger. Microbiol. Mol. Biol. Rev. 77:1-52.

Römling, U., Gomelsky, M., and Galperin, M. Y. 2005. C-di-GMP: The dawning of a novel bacterial signalling system. Mol. Microbiol. 57:629-639.

Römling, U., and Simm, R. 2009. Prevailing concepts of c-di-GMP signaling. Pages 161-181 in: Bacterial Sensing and Signaling. Karger Publishers, Basel, Switzerland. doi: 10.1159/000219379.

Schäfer, A., Tauch, A., Jäger, W., Kalinowski, J., Thierbach, G., and Pühler, A. 1994. Small mobilizable multi-purpose cloning vectors derived from the Escherichia coli plasmids pK18 and pK19: Selection of defined deletions in the chromosome of Corynebacterium glutamicum. Gene 145:69-73.

Schirmer, T., and Jenal, U. 2009. Structural and mechanistic determinants of c-di-GMP signalling. Nat. Rev. Microbiol. 7:724-735.

Shen, Y., Chern, M., Silva, F. G., and Ronald, P. 2001. Isolation of a Xanthomonas oryzae pv. oryzae flagellar operon region and molecular characterization of flhF. Mol. Plant-Microbe Interact 14:204-213.

Su, J., Zou, X., Huang, L., Bai, T., Liu, S., Yuan, M., Chou, S. H., He, Y. W., Wang, H., and He, J. 2016. DgcA, a diguanylate cyclase from Xanthomonas oryzae pv. oryzae regulates bacterial pathogenicity on rice. Sci. Rep. 6:25978.

Tang, J. L., Feng, J. X., Li, Q. Q., Wen, H. X., Zhou, D. L., Wilson, T. J., Dow, J. M., Ma, Q. S., and Daniels, M. J. 1996. Cloning and characterization of the $\mathrm{rpfC}$ gene of Xanthomonas oryzae pv. oryzae: Involvement in exopolysaccharide production and virulence to rice. Mol. Plant-Microbe Interact 9:664-666.

Trampari, E., Stevenson, C. E. M., Little, R. H., Wilhelm, T., Lawson, D. M., and Malone, J. G. 2015. Bacterial rotary export ATPases are allosterically regulated by the nucleotide second messenger cyclic-diGMP. J. Biol. Chem. 290:24470-24483.

Valentini, M., and Filloux, A. 2019. Multiple roles of c-di-GMP signaling in bacterial pathogenesis. Annu. Rev. Microbiol. 73:387-406.

Varani, A. M., Monteiro-Vitorello, C. B., Nakaya, H. I., and Van Sluys, M.-A. 2013. The role of prophage in plant-pathogenic bacteria. Annu. Rev. Phytopathol. 51:429-451.

Wang, F. F., Cheng, S. T., Wu, Y., Ren, B. Z., and Qian, W. 2017. A bacterial receptor PcrK senses the plant hormone cytokinin to promote adaptation to oxidative stress. Cell Rep. 21:2940-2951.

Wang, L., Makino, S., Subedee, A., and Bogdanove, A. J. 2007. Novel candidate virulence factors in rice pathogen Xanthomonas oryzae pv. oryzicola as revealed by mutational analysis. Appl. Environ. Microbiol. 73:8023-8027.

Wang, Y., Li, Y., Wang, J., and Wang, X. 2018. FleQ regulates both the type VI secretion system and flagella in Pseudomonas putida. Biotechnol. Appl. Biochem. 65:419-427.
White, F. F., and Yang, B. 2009. Host and pathogen factors controlling the rice-Xanthomonas oryzae interaction. Plant Physiol. 150:1677-1686.

Whitney, J. C., Colvin, K. M., Marmont, L. S., Robinson, H., Parsek, M. R., and Howell, P. L. 2012. Structure of the cytoplasmic region of PelD, a degenerate diguanylate cyclase receptor that regulates exopolysaccharide production in Pseudomonas aeruginosa. J. Biol. Chem. 287:23582-23593.

Wiśniewski, J. R., Zougman, A., Nagaraj, N., and Mann, M. 2009. Universal sample preparation method for proteome analysis. Nat. Methods 6:359-362.

Wuichet, K., and Zhulin, I. B. 2010. Origins and diversification of a complex signal transduction system in prokaryotes. Sci. Signal. 3:ra50.

$\mathrm{Xu}, \mathrm{J} ., \mathrm{Wu}, \mathrm{M}$., and He, C. 2010. Identification and functional analysis of Tdrxoo, the member of TonB-dependent-receptor family proteins in Xanthomonas oryzae pv. oryzae. Acta Microbiol. Sin. 50:155-161.

Xue, D., Tian, F., Yang, F., Chen, H., Yuan, X., Yang, C. H., Chen, Y., Wang, Q., and He, C. 2018. Phosphodiesterase EdpX1 promotes Xanthomonas oryzae pv. oryzae virulence, exopolysaccharide production and biofilm formation. Appl. Environ. Microbiol. 84:e01717-18.

Yang, F., Qian, S., Tian, F., Chen, H., Hutchins, W., Yang, C. H., and He, C 2016. The GGDEF-domain protein GdpX1 attenuates motility, exopolysaccharide production and virulence in Xanthomonas oryzae pv. oryzae. J. Appl. Microbiol. 120:1646-1657.

Yang, F., Tian, F., Chen, H., Hutchins, W., Yang, C. H., and He, C. 2015. The Xanthomonas oryzae pv. oryzae PilZ domain proteins function differentially in cyclic di-GMP binding, and regulation of virulence and motility. Appl. Environ. Microbiol. 81:4358-4367.

Yang, F., Tian, F., Li, X., Fan, S., Chen, H., Wu, M., Yang, C. H., and He, C. 2014. The degenerate EAL-GGDEF domain protein Filp functions as a cyclic di-GMP receptor and specifically interacts with the PilZ-domain protein PXO_02715 to regulate virulence in Xanthomonas oryzae pv. oryzae. Mol. Plant-Microbe Interact 27:578-589.

Yang, F., Tian, F., Sun, L., Chen, H., Wu, M., Yang, C. H., and He, C. 2012. A novel two-component system PdeK/PdeR regulates c-di-GMP turnover and virulence of Xanthomonas oryzae pv. oryzae. Mol. PlantMicrobe Interact 25:1361-1369.

Yang, F., Xue, D., Tian, F., Hutchins, W., Yang, C. H., and He, C. 2019. Identification of c-di-GMP signaling components in Xanthomonas oryzae and their orthologs in Xanthomonads involved in regulation of bacterial virulence expression. Front. Microbiol. 10:1402.

Yi, X., Yamazaki, A., Biddle, E., Zeng, Q., and Yang, C. H. 2010. Genetic analysis of two phosphodiesterases reveals cyclic diguanylate regulation of virulence factors in Dickeya dadantii. Mol. Microbiol. 77: 787-800.

Zhu, P. C., Li, Y. M., Yang, X., Zou, H. F., Zhu, X. L., Niu, X. N., Xu, L. H., Jiang, W., Huang, S., Tang, J. L., and He, Y. Q. 2019. Type VI secretion system is not required for virulence on rice but for inter-bacterial competition in Xanthomonas oryzae pv. oryzicola. Res. Microbiol. 171:64-73.

Zou, L. F., Li, Y. R., and Chen, G. Y. 2011. A non-marker mutagenesis strategy to generate poly-hrp gene mutants in the rice pathogen Xanthomonas oryzae pv. oryzicola. Agric. Sci. China 10:1139-1150.

Zou, Q. H., Li, Q. H., Zhu, H. Y., Feng, Y., Li, Y. G., Johnston, R. N., Liu, G. R., and Liu, S. L. 2010. SPC-P1: A pathogenicity-associated prophage of Salmonella paratyphi C. BMC Genomics 11:729. 